\title{
TERRITORIALITY, NEST DISPERSION, AND COMMUNITY STRUCTURE IN ANTS.
}

\author{
By Sally C. Levings ${ }^{1}$ and James F. A. Traniello ${ }^{2}$
}

\section{INTRODUCTION}

The dispersion patterns of ant colonies have been reported for a variety of species having very different ecological characteristics (Pontin 1961; Yasuno 1963, 1964a,b, 1965; Brian 1964; Brian et al. 1965, 1966; Greenslade 1971; Room 1971, 1975a,b; Bernstein and Gobbel 1979; Levings and Franks 1982), and typically, spacing studies involve discussions of territoriality. Recently, Hölldobler and Lumsden (1980), using a cost/ benefit approach, examined the importance of the economic defensibility of territories and its influence on the use of space and dispersion patterns. Hölldobler $(1974,1976 a, 1979 a, b)$ demonstrated the relationship between resource distribution, territory shape and nest spacing. These studies also emphasize that in order to understand thoroughly territoriality and other intra- and interspecific relationships, it is necessary to comprehend the role of social design in the establishment and maintenance of territory. Without such a combined approach of behavior and ecology, it is difficult to assess accurately the significance of territoriality in social species such as ants.

In many studies there have been problems in the application of the term territoriality and discrepancies in the identification of territorial phenomena. Terms describing the use of foraging area such as territory and home range have been rather poorly defined and vary in meaning between authors. Territory to some authors denotes a defended area (Baroni-Urbani 1979; Hölldobler 1974, 1976a; Hölldober and Wilson 1977a,b; Hölldobler and Lumsden 1980) whereas to others it is synonymous with home range or is casually used (Dobrzanska 1958, 1966). There are also problems with the application of information on territoriality in the interpretation of spacing patterns. For example, mathematical evidence of

\footnotetext{
${ }^{1}$ Museum of Comparative Zoology Laboratories, Harvard University, Cambridge, Mass. 02138.

${ }^{2}$ Department of Biology, Boston University, Boston, Mass. 02215 [To whom reprint requests should be sent].

Manuscript received by the editor June 19, 1981.
} 
nest overdispersion is frequently confused with, or taken as evidence for, territoriality although crucial behavioral patterns are not considered. However, sufficient information is available in the literature to suggest some of the behavioral and ecological factors important in the regulation of nest distribution.

With the above cautions in mind, we here present a simple model of predicted spatial distributions of colonies under different ecological conditions. We then survey the literature to examine the fit of available data to our predictions. Finally we discuss the general problem of the form of interactions between colonies and some of the implications of this for both field and theoretical considerations.

\section{Theoretical Aspects of Nest Distribution Patterns.}

We would first like to develop a set of biologically realistic predicted spatial distributions of colonies. We begin by positing some simple assumptions about a hypothetical ant population:

1. Nest sites are unlimited.

2. The habitat is homogenous and inhabited by a single species.

3. Each colony forages symmetrically around the nest to some distance $r$, which forms the radius of a circle. Within this circle, no other colonies can forage or become established.

Simberloff (1979) derives the maximum foraging distance, $r$, as

$$
r=\frac{\sqrt{2}}{\sqrt[4]{3} \sqrt{\mathrm{p}}}
$$

where $p$ is the density of nests. In this case, nests are hexagonally packed and the array of nests is overdispersed (more regularly spaced than expected if random; Figure 1, case 1). Nests are spaced $2 r$ apart and have 6 equidistant nearest neighbors.

Under different ecological conditions, the expected spatial distribution of nests will change. In low density populations, nest distribution should reflect the best foraging or nest sites; nests may be dispersed in any way and should tend towards a random distribution (Figure 1, case 2). Internest distance should on the average be at least twice $r$ and usually more; its variance should be high. If nest sites are not uniformly available, then nest spacing will 
depend upon whether or not nest sites are farther apart or closer together than this distance. We predict one of 2 patterns: (1) nests will be more overdispersed than potential nest sites (Case 3a) or (2) although nests may be clumped in space, foraging ranges which are asymmetric and which partition foragers will develop (Case $3 b$ ). If potential nest sites are farther apart than twice $r$, then nests will be distributed only with respect to potential nest sites. The effects of habitat heterogeneity will depend upon the scale and extent of the patchiness in relation to the foraging range of a species. If patches hold several to many colonies, then clumps of nests which are overdispersed within the clump are predicted. Smaller patches in complex mosaics will not generate predictable nest distributions unless the arrays of patches are very regularly distributed.

The effect of adding more species to the system will depend upon the species. Generally, in multi-species systems, the level of repulsion observed between co-occurring species should be directly proportional to the amount of overlap in resource use. Species utilization curves can range in overlap from 0 to essentially complete ecological identity ( $100 \%$ overlap). Predicted spatial patterns will clearly depend on the actual distribution of species. If two or more species with identical requirements and foraging radii occur in the same area, interactions within and between species should be equally strong. In this case, the pattern of nest distribution predicted is random for any one species (Franks 1980; Levings and Franks 1982). Nests should be overdispersed, but each species is distributed with respect to every other species (i.e., nests of all species are treated as equivalents). In addition, there should be no pattern in the species identity of nearest neighbors (Case 4). Removal of any one species should have the effect of the removal of a nest at random from an overdispersed array; the degree of observed overdispersion should decrease. The spatial dispersion of any one species in such an array should tend to look like a low density nest population (Case 2), but the history of the area may cause any type of pattern under different conditions.

If two or more species have the same foraging radius but do not overlap $100 \%$ in resource requirements, intraspecific interactions should be stronger than interspecific interactions (Case 5). We predict that (1) the entire array will be overdispersed and (2) each species will also be overdispersed from itself. Franks (1980) and 


\section{FIGURE 1}

Case 1 High density population

Assumptions: 1 . Single species

2. All nests have the same $r$

3. Unrestricted nest sites

Predictions: 1. Overdispersed nest array

2. Nest to nest distance $=2 r$

Case 2 Low density population

Assumptions: $\quad 1,2,3$

Predictions: 1. Nest distribution will tend to randomness

2. Average nest to nest distance $>2 r$

3. High variance in nest to nest distance

Case 3 Limited nest sites

a. Assumptions: 1, 2

Predictions: 1. Nests more overdispersed than potential nest sites

2. Nest spacing will vary with nest site location, minimum nest to nest distance $=2 r$, average nest to nest distance $>2 r$

3. High variance in nest to nest distance

b. Assumptions: 1

Predictions: 1. Nests distributed as nest sites

2. Asymmetric foraging ranges

Case 4 Intraspecific $=$ interspecific interactions

Assumptions: $\quad 2,3$

Predictions: 1. Entire nest array overdispersed

2. Individual species are more randomly dispersed than the total array

3. No pattern in the identity of nearest neighbor

4. High variance in nest to nest distances within a species, average nest to nest distance $>2 r$

5. Low variance in nest to nest distances for the entire array, average nest to nest distance $=2 r$

Case 5 Intraspecific interactions $>$ interspecific interactions

Assumptions:

2, 3

Predictions:

1. Entire nest array overdispersed

2. Individual species within the array are also overdispersed

3. Nearest neighbors tend to be members of other species

4. Low variance in nest to nest distances within species, average nest to nest distance $>2 r$

5. Low variance in internest distances for the entire array, average nest to nest distance $=2 r$ 
CASE I

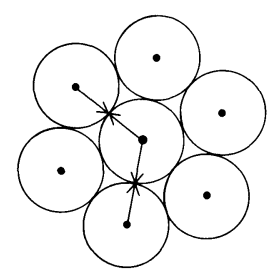

CASE 3a

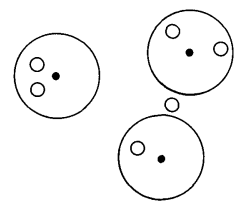

CASE 4

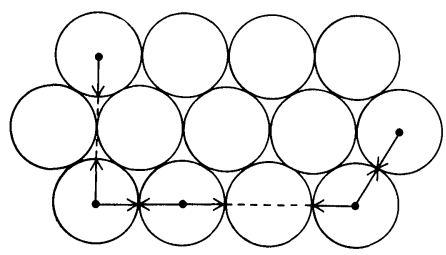

CASE 2

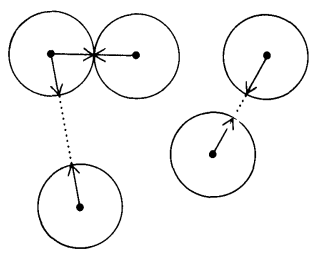

CASE 3b

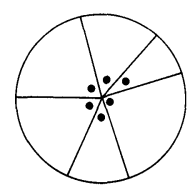

$\leftarrow R$

potential nest site

Figure 1. Theoretical nest dispersion patterns under different ecological conditions. Additional details in text.

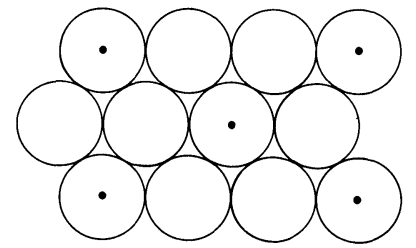


Levings and Franks (1982) have reviewed the relevant statistical literature and give a suggested procedure for examining this problem.

In addition to changes in the observed spatial array of any one species, in multi-species populations, there should be correlated changes in expected internest distances under different competitive regimes. If intra- and interspecific interactions are equally strong, the average internest distance within any one species should be longer than twice the species' average $r$ and the variance in between nest distances within any one species should be high (essentially a low density population, Case 2). If intraspecific interactions are more important than interspecific interactions, then internest distance within any one species should be greater than twice the species' average $r$ and their variance should be relatively low. The exact predicted distance will be a function of the number of interacting species and their relative abundances. It may be possible to use the degree of departure from predicted intraspecific spacing patterns as a measure of competition between species in homogenous habitats. If intranest distances within a species are $2 r$, then it does not appear to be interacting significantly with sympatric species, at least not in ways which affect its spatial distribution.

\section{Detection of Overdispersion and Methodological Problems}

There are certain methodological difficulties in applying any sort of spatial analysis to previously published data on nest distributions. In particular, the complicated structure of the nests of many species has confused workers, especially when many nest entrances are present. In Lasius neoniger, Headley (1941) assumed that the species was unicolonial, since he could only occasionally elicit aggression between adjacent nest entrances. In fact, $L$. neoniger colonies are distinct and well organized, but extensive field tests are required to delineate colony boundaries (Traniello 1980). Simple mapping of nest openings may reflect the distribution of colonies fairly well (as it does for many species in the ground ant community in Panama, Levings and Franks 1982; Levings, personal observations), but may lead to confusion unless sufficient data on the species are available (see, for example, Brough 1976). Whitford et al. (1980) assumed that workers of Novomessor cockerelli were entering an alien nest because they did not return to the same nest 
entrance from which they departed. However, Hölldobler et al. (1978) and Davidson (1980) documented that this species has nests with multiple entrances.

Although there are several methods for the detection of overdispersion (Pielou 1977), we have chosen to apply Clark and Evans' (1954) nearest neighbor (NN) technique wherever possible. It is based upon the ratio between the observed mean nearest neighbor distance and the expected distance when a population is distribution at random. The index $R$ can range from 0 (perfect aggregation) to 2.1491 (perfect hexagonal overdispersion). A value of 1 indicates a random dispersion pattern. The significance of $R$ is tested using the $\mathrm{z}$ transformation. In an overdispersed population, the observed mean nearest neighbor distance is larger and the variance in nest to nest distance is lower than it would be in a randomly distributed population. Thus a population which is significantly overdispersed using this measure confirms 2 of our predictions (overdispersion and low variance in $\mathrm{NN}$ distance). Other methods do not have this property.

In our evaluation of spacing information in the literature, if we were unable to apply nearest neighbor methods, but complete quadrat counts were published, we calculated variance/mean ratios and tested them for significance using $X^{2}$ statistics (Pielou 1977). A $\mathrm{V} / \mathrm{M}$ ratio of less than 1 indicates overdispersion while values greater than 1 indicate clumping. Cases are included in which data are not sufficient to test for statistical overdispersion, but information on partitioning of resources or area was published. We have organized the available data by geographic region, habitat and food types (Table 1). Methods used in gathering previously unpublished data will be described with the specific set of data. In testing our model and spatial predictions from the literature, we are limited by the previous interests and focus of other authors. We are able to test the spatial predictions far more thoroughly than the hypotheses about the actual expected distances between nests, but there is no empirical reason that they cannot be experimentally verified in the field (see discussion).

Data are discussed by subdividing reported cases into groups according to foraging type: (1) species which do not defend resources although they may or may not recruit to food, (2) species which defend randomly and unpredictably distributed resources (e.g., dead insects, which are patchy in both space and time), (3) 
species which defend predictable and persistent resources (e.g., honeydew from aphids, resources which are patchy in space but not in time) and (4) truly territorial species which defend area which has potential food resources. These divisions mark some ecologically important foraging types within communites.

\section{Observed Patterns}

\section{Nest Defense}

The data suggest that species which display only nest defense fall into 4 major groups, depending upon the details of their foraging biology. First, some species forage only as solitary individuals for food items which a single forager can subdue and retrieve (Group I foragers, Oster and Wilson, 1978). Examples of this group include most Dacetini, many Ponerinae, and some of the non-leaf cutting Attini (Brown and Wilson 1959, Wilson 1971, Oster and Wilson 1978).

There is very little applicable data on this group. The frequency of dacetine nests in extensive Berlese sampling of a tropical deciduous forest fit a Poisson distribution indicating a random distribution (Levings, unpublished data), but this sort of data does not differentiate between the suitability of the site or other important factors in the distribution of nests. Certainly there was no indication that nests were clumped. The maximum number of nests found was 6 in 84 $0.25 \mathrm{~m}^{2}$ samples. When a truncated Poisson was fit $(0$ class excluded), the distribution did not differ from Poisson expectation $\left(\mathrm{p}>0.5, \chi^{2}\right.$ test).

Second, some species may recruit nestmates to food resources, but make no attempt to defend them, decamping if another, more aggressive, species arrives before the food is retrieved (Group II, in part, Oster and Wilson 1978). These species specialize in the rapid location and removal of food. Examples include Paratrechina longicornis and Tapinoma melanocephalum (Wilson 1971). No data on their nest distribution is available, but many are known to form small fragmented colonies which move frequently between ephemeral nest sites.

The third set of species have developed mechanisms for feeding at the same resources as other, more aggressive ants, without eliciting defensive reactions (Groups I \& II, in part, Oster and Wilson 1978, Wilson 1971). It is not known how much of a colony's food intake 
results from such theft and how much is independently gathered. Examples include Leptothorax acervorum and various Cardiocondyla species (Brian 1955; Wilson 1959a, 1971). These species usually recruit few other workers to the food item; many of these species recruit only one other nestmate using tandem running (Wilson 1959a). No spacing information is available for these species.

The fourth set of species include the legionary ants (true group foragers) and most of the specialists on extremely difficult prey (Groups IV and V, Oster and Wilson 1978). These species defend only their nest sites (which may move often) and forage in various sized groups. The most spectacular examples of this type of foraging are the army ants (Schneirla 1971). Specialists on difficult prey occur in several genera (examples, Pachycondyla (=Termitopone), Leptogenys, Gnamptogenys); specialized retrieval methods may involve extensive cooperative foraging (Wilson 1971). Little nest spacing information is recorded about these groups. Army ants of several genera have been observed to avoid each other when they meet in the field, but no similar information is available for related groups (Schneirla 1971). Other legionary groups are relatively rare on $\mathrm{BCI}$ and, in 4 years of field work, no interactions were observed (Levings, personal observation).

In general, information on spacing patterns of ants which defend only their nests is extremely difficult to gather, since the investigator must usually depend upon luck to locate colonies and will never be certain that all colonies in an area have been found. Because information on foraging ranges for most species is unavailable, we are unable to test those aspects of our hypotheses. Many species which are now assumed to defend only their nest sites may well be found to defend either resources or a foraging territory.

\section{Resource defense}

a. short term

The defense of unpredictable resources occurs on varying time scales. Resources which persist for very short periods (i.e., minutes for most dead insects) are defended by many generalist or scavenging ants during the recruitment/retrieval process (Groups II \& III, in part, Oster and Wilson 1978). Spatial overdispersion in densely populated areas has been shown in one complex tropical community (Levings and Franks 1982). It is probably typical of many 
reported cases of overdispersion in temperate ground ant communities dominated by relatively few generalist species (most species of the genera Myrmica, Tetramorium, Lasius, Aphaenogaster, some Formica; Table 1). Some species are placed here somewhat arbitrarily because good foraging ecology data are not available.

In more complex (i.e., non-uniform) habitats, the pattern of nest spacing is reported to be directly related to environmental conditions. Lasius flavus, which has been intensively studied in several European habitats, displays different nest distributions between locations. Waloff and Blackith (1962; Table 1) found that nests were overdispersed in a high density population and tended toward randomness in a low density population. In a wet, low pasture with limited nest sites, nests were also overdispersed (Blackith et al., 1963, Table 1). With Myrmica rubra present in a low density population, L. flavus was randomly distributed (Elmes 1974). However, the partial segregation of species indicated that both intra- and interspecific interactions were present; $M$. rubra nests were more overdispersed than potential nest sites (Table 1). Similar patterns have been noted in other species. Petal (1972) showed that the pattern of distribution in Myrmica laevinodis depended upon the scale with which the species was examined. Within the habitat, nests were clumped, but within clumps of nests on a small scale, nests were either overdispersed or randomly distributed. In another study, Petal (1977) linked observed nest distribution and the available food supply in Myrmica lemanica. In a year with low food abundance, nests were overdispersed; when food was abundant, nest distribution was random, tending to aggregation. Petal did not state if she distinguished between nests and nest openings by testing aggressive responses between colonies. However, overall nest density remained approximately the same. Most other studies have assumed but not demonstrated the correlation between food abundance and nest dispersion patterns.

Within colonies with multiple nest entrances, the distance between nest entrances should be approximately $2 r$ and nest entrances should be overdispersed if avoiding redundant search is the underlying cause of polydomy. This appears to be the case in Lasius neoniger. Each nest is composed of a series of nest entrances which are overdispersed within a colony (Traniello 1980). L. neoniger is unable to retrieve prey effectively further than approximately $15 \mathrm{~cm}$ from any given nest opening due to interference from other species 
or congeners (Traniello, 1980). Inter-opening distances are not statistically different from $30 \mathrm{~cm}$ in a set of 12 nests with varying numbers of nest openings $(P>0.10$, $t$ test, $11 / 12$ cases; range 2-27 nest entrances), fitting our predictions quite well. The only nest with consistently closer inter-opening spacing was hemmed in by 3 larger nests; its openings occupied essentially the entire available area (18 $\mathrm{cm}$ between entrances, 4 entrances). Although this species fits our predictions, we are unable to test them further with other species, either within species between nest openings or between separate nests. Nest entrance patterns of Paltothyreus tarsatus, which is also a polydomous species, appear to be similar in function to those of $L$. neoniger (Hölldobler, personal communication). However, in polydomous species of Camponotus, Atta and Pheidole, nest entrances are often much less than $2 r$ apart (Yasuno 1964a; Hölldobler and Möglich 1980). Therefore,the association between foraging ecology and nest structure probably depends on the details of the biology of individual species.

When resources persist for slightly longer time periods (patches that can be exploited in a few days such as rotting fruit), we also expect overdispersion of nests. This pattern has been confirmed in several species. Myrmecocystus mimicus nests in desert areas and exploits patchy, unpredictable concentrations of termites which form a major part of its diet (Table 1, Hölldobler 1976b, 1979a, Hölldobler and Lumsden 1980). During the retrieval of these patches of food, a nest will defend the area by engaging surrounding nests in a complex ritualized display and battle ("tournamenting") which may result in the destruction of incipient colonies. Normally, the tournamenting behavior persists until the patch is exploited; searching in the area continues during this time. Nests are overdispersed (G. Alpert, personal communication). Nests of Prenolepsis imparis are overdispersed (Table 1), and workers defend pieces of fruit for 1 or more days. This species has also been observed to tournament as Myrmecocystus mimicus does (Traniello, unpublished observations). It appears that in these species the cost of allocating a portion of the worker force to engage foragers from a neighboring nest in tournaments that prevent their access to a resource is less than the benefits obtained from these patchily distributed food sources (Hölldobler and Lumsden 1980).

b. persistent resources

Persistent resources vary in their importance to colonies, depend- 
ing on their nutritional value, and can differ from a branch with a few aphids to a large homopteran population which provides most of a colony's food intake. The degree to which a colony depends upon persistent resources will approximately determine the intensity of their defense. Formica fusca tends only a very few aphids and can be chased from them relatively easily (Brian 1955), while $F$. rufa colonies regularly destroy each other in battles for the control of specific trees (Elton 1932, Skinner 1980). Therefore, the removal of persistent resources can affect colonies differently; some nests will die if they are deprived of them (Elton 1932). In this section we will only consider species which are dependent, at least in part, upon such resources (Groups II \& III, in part, Oster and Wilson 1978).

Most studies on the defense of persistent resources concern the genera Formica and Pogonomyrmex. The patterns of their nest distribution depends upon colony structure, nest site requirements and habitat complexity. Most Formica nest distributions are the result of the interaction between the need for high insolation of the nest and the proximity of trees or bushes which are suitable for tending aphids. Many species nest along the ecotones between fields and forests, in forests, and in forest clearings ( $F$. lugubris, $F$. schaufussi, $F$. exsectoides, F. polyctena, F. rufa, F. ulkei). These species will be found in overdispersed arrays only if habitat patches are found in rather predictable patterns. These are clearly special cases and explain some of the variation between authors for some species (see for example, $F$. lugubris, Table 1 ). We expect the linear distance along the ecotone to be relatively even in this case, but we have no data to test this hypothesis. Casual observations on $F$. schaufussi tend to support this (Traniello, personal observations). Formica species which nest in fields should be found in overdispersed arrays; the few reports that exist indicate that they are $(F$. uralensis, $F$. opaciventris, $F$. fusca, $F$. pratensis, Table 1). In addition, Pogonomyrmex species which defend patches of seeds are found in overdispersed arrays. These and other species that defend persistent resources and are not nest site limited are in general found in overdispersed arrays (Atta spp., Acromyrmex octospinosus, Lasius niger, etc., Table 1).

Colonies which depend upon persistent resources frequently organize resource defense and utilization with trunk trails. Trunk trails are long term routes which are marked with persistent trail 
pheromones (Hölldobler, 1974, 1976a; Traniello, 1980; Group III, Oster and Wilson, 1978). Thus both the track to the resource and the resource itself constitute the defended area. These foraging ranges are highly asymmetric-foragers from different colonies are only likely to interact when trail systems overlap. Essentially all foragers follow these trails in some species (Hölldobler, 1976a), but this varies a great deal from group to group. In general, we expect that nest to nest distances will be shorter than the distance to the defended resource if colonies have highly skewed foraging. This prediction is born out in a study of three sympatric species of Pogonomyrmex (Hölldobler, 1976a). Between nest distances are shorter in the two interspecifically defending species which forage on trunk trails than between nests of the individually foraging $P$. maricopa.

3. Defense of area

We consider defense of space larger in area than nest yards or core areas (Hölldobler 1976a) to be true territoriality. This defense of area is, in essence, defense of potential foraging grounds. Only a few ant species, characterized by complex mechanisms of mass recruitment and high levels of intra- and interspecific aggression, are therefore truly territorial in our classification. Most dominant tropical canopy ants (some members of the genera Azteca, Oecophylla, Crematogaster, Camponotus, Monacis, Polyrachis, Anoplolepis, Table 1) and at least one member of the genus Solenopsis are truly territorial. We must point out that in some cases the distinction between true territoriality and resource defense is not perfectly clear, and that strategies of territorial defense and resource defense are at times difficult to distinguish.

Solenopsis invicta, an introduced species from South America, has been extensively studied in the southern United States where it may form monocultures in fields (Wilson et al. 1972). Extensive mapping of one population showed overdispersion of nests maintained over time despite frequent nest movement (Eisenberg 1972, Table 1).

Maps of intercolony dispersion have been published for a number of ant species in tree crops in tropical areas (Table 1). Individual colonies hold territories in the canopy both intra- and interspecifically. The distribution of the canopy mosaic of dominants can have a very complex structure (Way 1953; Greenslade 1971; Majer 
1976a,b). Individual colonies are clearly separated from each other, frequently by a no ant's land between defended areas (Hölldobler 1979b).

However, the statistical dispersion of these colonies is difficult to assess. Territory size varies a great deal between species because population structure has very strong effects on colony size and organization. Only a few polydomous, polygynous colonies may occupy extensive areas (Steyn 1954, Greenslade 1971, Leston 1973, Majer 1976a,b). The dispersion of volumes in space is difficult to treat statistically from published data although 3-dimensional methods exist (Clark and Evans 1979, Simberloff 1979). Luckily, the biological evidence for dispersion and nonoverlap of area is overwhelming. Territorial battles are commonly observed and, in populations followed over a number of years, control of a given area shifts from colony to colony and species to species. Although we predict statistical overdispersion, we are unable, for both statistical and biological reasons, to test for it in these cases. There is, however, no question about the existence of true territorial defense and the spatial separation of colonies.

Ant plants are a special set of cases of true territoriality. Several tropical tree species (Table 1) are coevolved with certain species of ants (some members of the genera Pseudomyrmex, Azteca or Pachysima) which protect the tree from herbivores or overgrowth in return for food and nest sites. Few other animals of any species are tolerated on the plant; the ant species are characteristically extremely aggressive. The mutualism is sufficiently old than at least one species parasitizes it by using the plant without protecting it in return (Janzen 1975). These ant colonies are thus distributed with respect to the distribution of their host and form distinct territories within the canopy mosaic. They may also help "grow" new host plants by affecting the survival of nearby seedlings (Janzen 1967, 1973).

\section{INTERCOLONY SpaCing EFFECTS}

Interspecific overdispersion is regularly reported in almost all habitats (Table 1). However, detailed ecological studies indicate that different mechanisms operate in different habitats. In part, this is due to the fact that the only necessary characteristic required to generate overdispersed arrays is the ability of a colony to interfere 
with colony foundation of potential competitors. Few studies have examined the pattern of species mingling. Brian and his co-workers have shown that nest sites probably limit many species in England, which apparently is a rather poor habitat for ants. The pattern of dominance over nest sites determines the location and abundance of many species (Brian 1952, 1956b, Brian et al. 1965). Nest density could be increased by providing new nest sites, and once established, populations remained relatively stable over long periods (Brian et al. 1966). Competition between species where nest sites were not as limiting tended to restrict individual species to areas which were close to optimal species requirements (Brian et al. 1966, Elmes 1971, 1974). These studies indicate that the details of species biology and physical tolerances may be critical, even in very simple habitats like heath. However, even in these systems, species are definitely not distributed independently of their competitors.

Tropical canopy dominants are associated with certain canopy conditions, and tend to be found mostly in shade or under certain other limited environmental states (Majer 1976a). Removal experiments indicate that colony foraging areas are competitively compressed; when a dominant is removed, surrounding colonies expand to fill the available space. Species usually found in one kind of canopy may expand into other types of foliage if adjacent dominants are extirpated (Majer 1976a,b). This pattern is similar to that found in far simpler grassland communities.

In a complex tropical ground ant community with at least 16 ecologically similar species, Levings and Franks (1982) have shown that new nests are not added at random to the nest array. Grouping all species, nests are overdispersed from each other. Each common species considered independently was also overdispersed.. This is interpreted as evidence that species are interacting more strongly intra- than interspecifically, but that interspecific effects were still important in determining nest distributions. Similar patterns in simpler communities indicate that this may be common (Table 1). The worst neighbor in a competitive sense should be identical to oneself. In any case, the simplifying assumption that species have identical requirements is almost infinitely unlikely to apply; even small differences in requirements or tolerances can be important in determining colony distributions. However, few adequate tests have been done and, in one published case, two closely related congeners, 
Pogonomyrmex rugosus and $P$. barbatus, essentially act like exact ecological equivalents (Hölldobler 1976a). Davidson (1977a) has suggested that the distribution of several individually foraging Pogonomyrmex (maricopa, californicus, desertorum and magnicanthus) is consistent with the hypothesis that they replace each other between habitats. The pattern could also occur in some other, less completely documented cases, perhaps in Atta (Rockwood 1973).

\section{Population Structure and Its Effects on the Spatial Distribution OF COLONIES}

Monogynous, queenright colonies are almost innevitably aggressive to conspecific nests or foragers, regardless of how territorial they are (Hölldobler and Wilson 1977c). Polygynous colonies may or may not display internest aggression. Hölldobler and Wilson (1977c) point out the importance of queen number in the maintenance of clear territorial borders. Species which commonly have polygynous colonies and/or those which adopt newly fertilized females to augment or replace females already in the nest do not always have strong intraspecific interactions; some do not form distinct colonies (Formica yessensis, F. lugubris, Table 1). In these cases the location of nests should be predominantly determined by ecological factors, in particular the kind of resource defense the colony shows. Thus some species should retain overdispersed patterns of nest distribution while other show clumped or random patterns (see model and predictions).

Examining this issue is complicated by the lack of population structure data for many species. Several Formica species which form unicolonial populations, but depend upon randomly and unpredictably distributed resources, are found in overdispersed arrays [those species found in fields: $F$. pratensis (provisionally), $F$. uralensis (provisionally), $F$. opaciventris, $F$. exsectoides, Table 1]; those which nest along the margins of a habitat and/or which defend persistent resources tend to have more random or clumped distributions $(F$. ulkei, $F$. rufa, $F$. lugubris, Table 1). Territory size in some tropical tree ants is partially a result of population structure. Many dominant species are polygynous and are able to expand their territories almost indefinitely under good ecological conditions (Greenslade 1971, Majer 1976a,b). In some cases, single 
queen species like Oecophylla may be at a disadvantage. Resistance to invasion or persistance of the nest may be limited by the female's egg production under some conditions, although this does not usually seem to be the case (Hölldobler and Wilson 1977c; Hölldobler and Lumsden 1980). We must emphasize that in populations with complex or variable structure it may be very difficult to determine the factors which are controlling distributions. Spacing may reflect foraging ecology as well as being an aspect of territoriality. More data are needed before good generalizations can be made.

\section{Behavioral and Ecological Aspects of Spacing}

For the cases we have been able to examine statistically, 67 out of 80 show overdispersed nest distributions or tend toward overdispersed nest distributions. The other 80 cases, which cannot be treated statistically, mainly have either overdispersed nest distributions or tend toward overdispersed nest distributions. Thus the majority of species studied tend to have regular nest arrays. This pattern holds despite the large number of species, food types and habitats considered. Species which defend only their nests are too rare to consider in our sample.

Our basic assumption is that no colony can become established or forage within some radius $r$ of another colony. There is a biological basis for this assumption in the patterns of interference with colony establishment and foraging patterns. Therefore, to understand nest spacing it is important to understand the different levels of competition in ant communities. Fertilized females or incipient colonies are usually destroyed when they are encountered by foragers from established colonies (Wilson 1971). The specificity of this behavior varies between species depending in part on population structure (Hölldobler and Wilson 1977c, DeVroey 1979). There is some evidence that workers are more likely to attack females from conspecific nests or closely related species, especially in monogynous, queenright colonies, as has been shown in Pogonomyrmex (Hölldobler 1976a) and Myrmecocystus (Hölldobler, personal communication). The studies of Pontin (1960) and others (reviewed in Wilson 1971) suggest that such behavior is more often directed toward queens of the same species as the attacking workers.

Another factor which may operate during this period is resource depletion mediated by either direct interference or exploitation. 
Within the foraging radius of an established colony, there is likely to be less food available, even if the established colony ignores incipient colonies. The amount of depletion will depend on the amount of resource overlap. Because destruction of females and incipient colonies is frequently reported and resource depletion probably also affects colony persistence, the chance of a small colony becoming established is low. Wilson (1971) estimates that only $0.01 \%$ of all fertilized females survive to found successful nests. Therefore, established colonies tend to persist and interact over long periods, insofar as is known (Wilson 1971). Given this pattern, what is the form of the interaction and why are patterns of interspecific overdispersion so common?

According to current theory, species can segregate a habitat to avoid or lessen competition in several ways: microhabit partitioning, food size or type, and activity period (Pianka 1978). Further, equilibrium theory generally asserts that only a limited amount of overlap is tolerated on any given niche axis (MacArthur and Levins 1967; Colwell and Futuyma 1971). Species which are too similar should not be able to coexist and, over a long enough period, the superior competitor in the overlapping pair will drive the other species extinct. Although there are many problems with the assumptions of this argument, we will use its basic divisions to examine the patterns of overlap between co-occurring ant species. Ant species may be specialized along these three major axes. We will consider each potential kind of specialization in turn and evaluate the evidence that segregation of species along that factor is usually sufficient to prevent strong competitive interactions.

Species may be considered specialized on food types in 3 major ways: (1) restricted prey types (i.e., only centipedes), (2) specific size ranges of prey (i.e., only prey $1-3 \mathrm{~mm}$ in length) or (3) some combination of (1) and (2) (i.e., centipedes between 5 and $8 \mathrm{~mm}$ long). Different kinds of specializations will have different effects on colony structure, nest size and foraging strategy. Resource restriction is frequently based on the matching of mandible or head size to food size or type (the trophic appendage, Schoener 1971, see below). Resources which are retrieved by individual workers, not by coordinated action, are especially likely to be treated in this manner (for example, seeds for desert ants, collembolans for dacetines). The resistance of the food item to recovery is also important; items 
which do not resist (seeds) are more likely to be size matched than items which require more complex treatment from the ants. Nests of specialist species may be restricted to areas which contain concentration of suitable prey (and as such violate the assumptions of our model). If resource size is matched with worker size class, then size polymorphism is one way to expand the resource spectrum of the colony without any changes in individual retrieval patterns (Oster and Wilson 1978). The development of coordinated retrieval mechanisms can further expand the accessible resource spectrum.

Almost all specialists, by definition, have less harvestable energy available to them than generalists. Thorne and Sebens (1981) suggest that species with low habitat quality (i.e., low food density) will have smaller nests than species with high quality areas (high food density). We extend this argument to predict that once a species has broadened its diet, it will include essentially all retrievable food types encountered. Such an increase in diet breadth is needed to support large colony sizes, based on almost any simple foraging efficiency model. Although specific prey types, especially those with noxious chemical defenses, require special handling methods, many prey types may be captured and/or retrieved by species with a limited behavioral repertoire. Certainly scavenged material can be handled by all but the most specialized mandibular types. Since ant colonies persist over years, they more or less continually require resources. Resource distributions are highly variable over time; prey types appear and disappear seasonally (Mabelis 1979; Levings and Windsor 1982). It is a general consequence of this that once a species generalizes its diet, it is likely to overlap strongly with one or more sympatric species. The value of large colony size is reflected in reproductive output. Numbers of reproductives usually increase with colony size to some upper limit (Wilson 1971). Since the chance of success for any given reproductive is low, high production will be likely to correlate with the largest probability of leaving successful offspring. Colonies which bud will tend to have higher rates of success if the new buds have large worker forces; this is also a function of energy intake. Colonies almost all require protein to raise brood (usually from insect prey or seeds) and many accept or require sugar to maintain adult workers (usually from Homoptera, fruit or nectaries). In general, large colony size is strongly associated with the maintenance of sugar 
resources. It appears that when adults can be fueled from sugar, more intensive foraging is possible and more brood and workers can be supported (Greenslade 1971; Leston 1973).

We do not deny that species which are specialized on prey types evolved resource segregation from competitive pressure. In fact, among specialized species which forage individually for prey, we expect some equilibrium co-existence theory to apply (see for example, Davidson 1980). We assert that there is no support for the contention that generalists segregate the resource spectrum to reduce competition (Wilson 1971). Available empirical studies indicate that high or essentially complete overlap in food type is frequent (Brian 1956a,b; Pontin 1961, 1963, 1969; Yasuno 1964a,b); Abe 1971; Hölldobler 1976a; Levieux 1977, Levings and Franks 1982). At best, partitioning of food type can account for only a small part of the observed pattern of species distribution in most habitats.

Habitat partitioning is a second possible method of limiting competitive interactions. Even in simple temperate grassland communities, co-occurring species forage at slightly different heights in the grass or tend to move more or less beneath the surface (Brian 1952, 1955, 1956b; Brian et al. 1966). However, all these species are usually described as being interspecifically territorial. Tropical faunas are well divided into arboreal and terrestrial components; many specialized species are further restricted to logs, rotting leaves or other microhabitats (Wilson 1959b, 1971; Carroll and Janzen 1973). Within these strata, high overlap between species resulting in intra- and interspecific aggression is frequently described (Carroll and Janzen 1973; Leston 1973; Greenslade 1975; Room 1975a,b).

Faunas may be further subdivided by time of foraging, if by foraging at different times, different resources are harvested. Time of foraging can differ daily (nocturnal vs. diurnal, Carroll and Janzen 1973), seasonally (Prenolepis imparis which forages in early spring and late fall, Talbot 1943, Lynch et al., 1980) or may track environmental cues, such as desert species that forage after rains (Bernstein 1974, 1979). Although it has not been proven, it is probable that generalist and scavenging species forage on different resources if they forage at different times, if there are temporal components to food availability. Most dead or readily captured prey do not remain available for long periods, few probably persist even hours (Carroll and Janzen 1973, Culver 1974, Traniello 1980). 
Other resources may be similarly affected-for example, winds may cover and uncover seeds in the desert (Reichman 1979). The option to forage at different times is not uniformly available to ant species; thermal tolerances may severely limit foraging time in both cold and hot climates or may affect the outcome of foraging contests (Hunt 1974; Davidson 1977a,b,; Hölldobler and Möglich 1980). Many species change the time of their foraging in the presence of competitors (Hunt 1974, Swain 1977). Thus foraging times may separate some species, but as in the case of food or habitat, high overlap between sets of sympatric species in foraging time is the norm, not the exception, in ant communities. The evolution of intra- and interspecific behaviors incuding complex patterns of food retrieval and defensive strategies has resulted from such high overlap.

The form and outcome of interactions between species is determined in large part by the mechanisms of recruitment and communication within species. The subtleties of recruitment communication and their effects on foraging ecology and interference competition are not appreciated by most ecologists. Behavioral mechanisms are so critical that we suggest that when examining the diet of a species, an investigator first ask why more items are not included. For many years harvester ants were considered to forage individually for seeds, but the field and laboratory studies of Hölldobler (1976a), Hölldobler and Wilson (1970) and Hölldobler et al. (1978) unequivocally demonstrated that species of Pogonomyrmex and Novomessor rely on a sophisticated array of recruitment behaviors in foraging. In Novmessor cockerelli, short-range recruitment, mediated by both chemical and vibrational signals, allows workers to move food sources quickly and thereby enables them to compete with sympatric species (Hölldobler et al. 1978; Markl and Hölldobler 1978).

Behavioral interactions, not food choice, seem to partition food resources among generalists. Protein foods (arthropod prey) tend to be highly unpredictable in time, space and size; adaptations to this resource distribution among generalists may be behavioral rather than morphological. Monomorium pharonis and Solenopsis fugax employ a chemical interference technique both defensively and offensively during foraging (Hölldobler 1973). Adams and Traniello (1981) have documented the ecological effects of recruitment and resource defense in Monomorium minimum, a north temperate 
open field ant. Monomorium minimum is a small (head width 0.47 $\mathrm{mm}$ ), monomorphic species. Workers are successful at retrieving food particles which are either extremely small (less than $0.5 \mathrm{mg}$ in weight) or large (greater than $450 \mathrm{mg}$ in weight). Most items of intermediate size are lost due to either exploitative or interference competition from other species. Detailed laboratory and field experiments on the organization of foraging showed that $M$. minimum recruits other workers to food sources using trail pheromones. The quantity of pheromone determines the foraging response of the colony. As trail pheromone concentration increases, more workers are recruited. The amount of trail pheromone deposited is dependent upon resource quality (in this case, measured by the investigators as weight). Large food items induce trail laying by many workers and therefore result in strong recruitment. If there is interference from another species while prey is being dissected, workers display a specific posture (gaster flagging) while extruding the sting and discharging a droplet of poison gland secretion. This secretion has a repellent effect on intruding ants and causes them to recoil and vigorously groom. The effectiveness of this defensive behavior is dependent on the number of workers recruited. Therefore, large prey, which elicit strong trail pheromone deposition, induce strong recruitment responses and this results in a worker force which can successfully defend the item during retrieval. The result of this feedback between prey size, pheromone concentration and colony response is a diet composed of small individually retrieved items and large items recovered by recruitment and successful defense.

Perhaps the best evidence for the importance of behavioral parameters in species interactions is the phenomenon of alarm specification. Certain ant species which interact strongly with other species may respond specifically to the presence of the competitor. The best studied case is that of Pheidole dentata and Solenopsis geminata (Wilson 1975). Pheidole dentata colonies respond to the presence of Solenopsis by a strong recruitment of major workers. Major workers proceed to attack and kill all Solenopsis encountered and to search thoroughly the area near where the Solenopsis workers were found. They do not respond to the odors or presence of other species with major worker recruitment. A similar pattern of response is indicated in the interactions between Oecophylla longi- 
noda and Camponotus sp. in Kenyan forest; alarm/recruitment specification may be the behavioral mechanism responsible for the structure and maintenance of the tropical canopy ant mosaic (Hölldobler 1979b).

In general, to defend any resource or area, including the nest, an ant must be able to summon her nestmates to a particular location. Within the nest, even quite primitive ants are able to communicate alarm and attract reinforcements (Robertson 1971; Traniello unpublished data). Outside the nest, recruitment is a necessary component of effective defense.

Ant species possess a wide diversity of recruitment communication techniques that are ecologically significant (see review by Hölldobler 1977). It is important to understand the ethology of social design to comprehend its role in ecological interaction. There are definite phylogenetic constraints and/or trends in the form of recruitment communication within the various subfamilies of ants (Hölldobler 1977). More primitive groups (some Ponerinae) usually recruit few workers to food sources; some group raiding species are exceptions. Mass recruitment is characteristic of some groups of Myrmicinae, Dolichoderinae and Formicinae. Each lineage has developed within certain paths involving specific glandular, physical and behavioral trends. These pathways are important in considering the evolution and development of ant community structure.

\section{SUMmaRy AND CONCLUSIONS}

We have argued that a very simple hypothesis is sufficient to generate predictions of spatial distributions of colonies under a variety of ecological settings. The majority of cases in the literature (Table 1) support the hypothesis that most ant species are regularly distributed with respect to conspecifics and other co-occurring species. We assert that this is a natural outcome of high overlap in food utilization in many species, and in particular, among generalists. We have suggested that departures from expected spatial patterns be used as a measure of competition between species, but too little information on colony foraging radii in relation to spacing patterns exists to test our hypotheses critically. More field measurements of colony foraging distances in relation to intercolony spacing are needed. Measurements of potential foraging distances when 


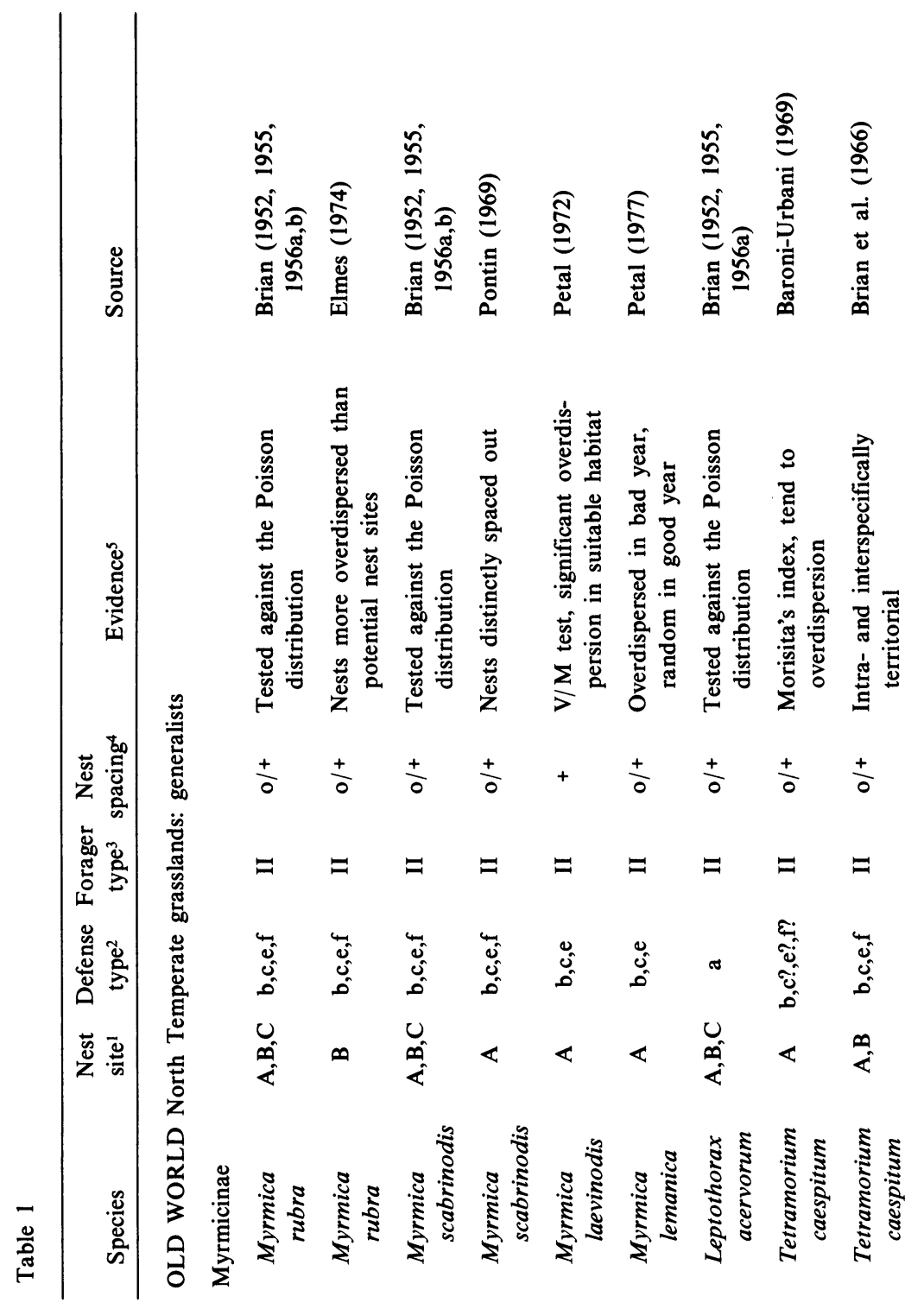




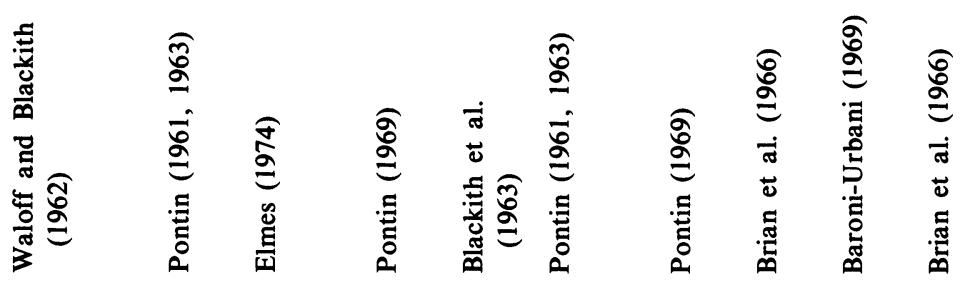

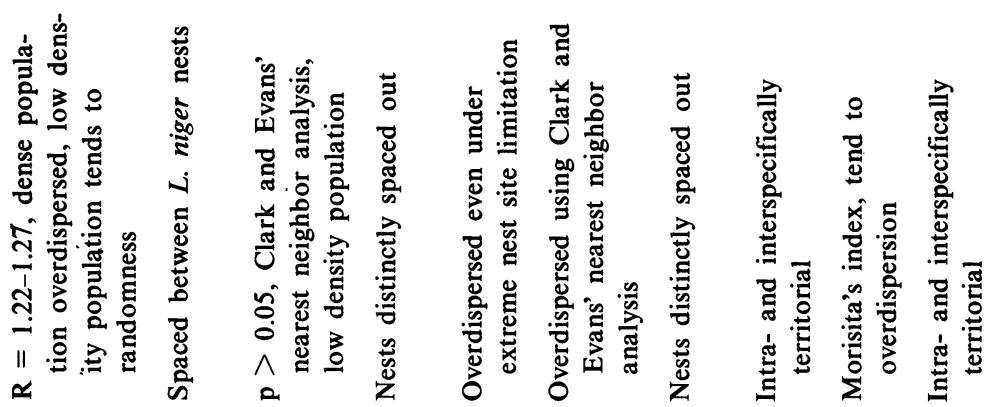

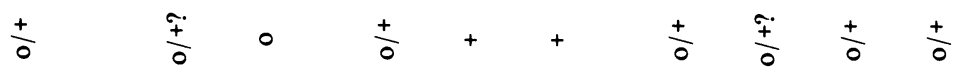

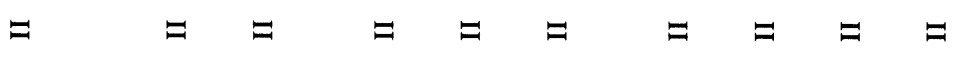

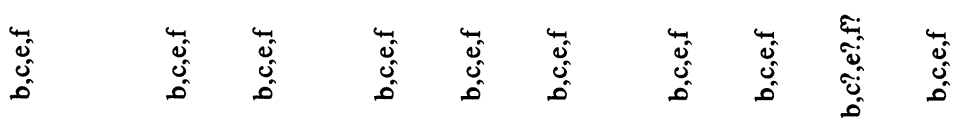
말 면

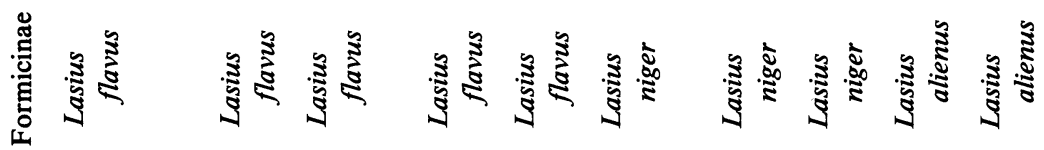




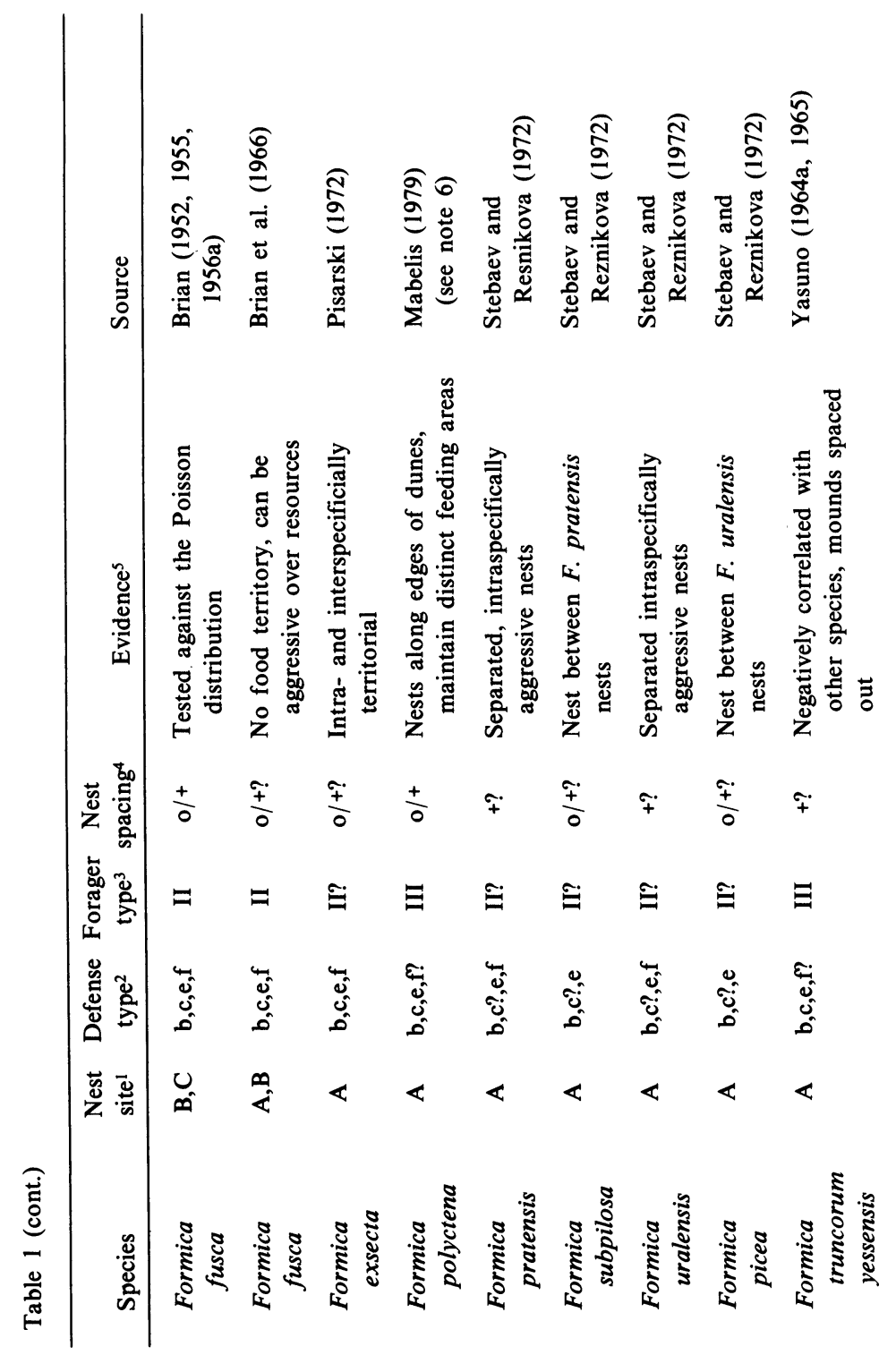



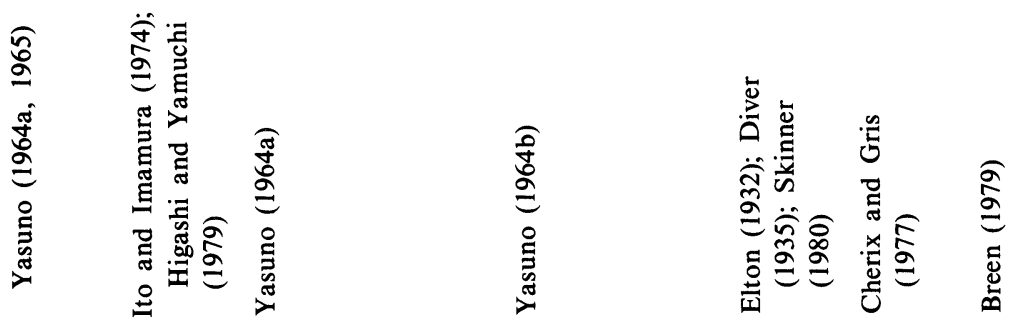

交

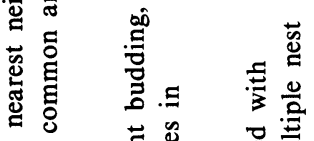

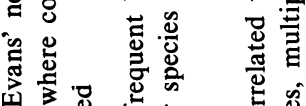

ये छ क्ये के

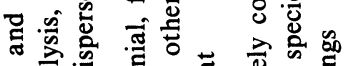

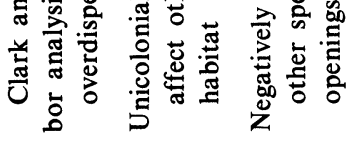

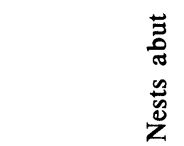

咅

$+\stackrel{+}{+}$

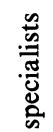

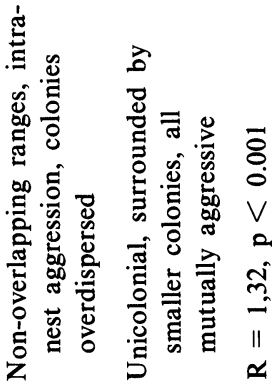

气

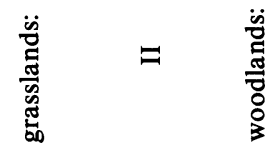

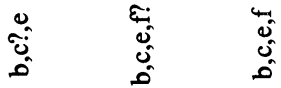

8

ప

苍

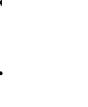

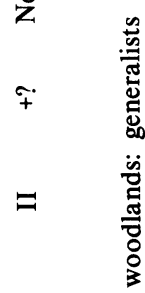

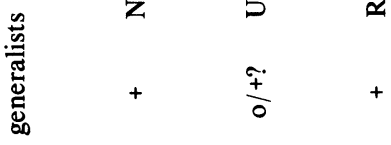

$\ll<<$

震

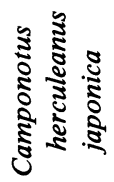

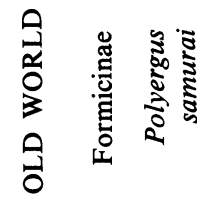

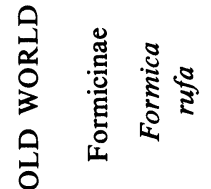

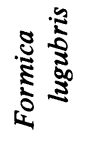

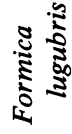




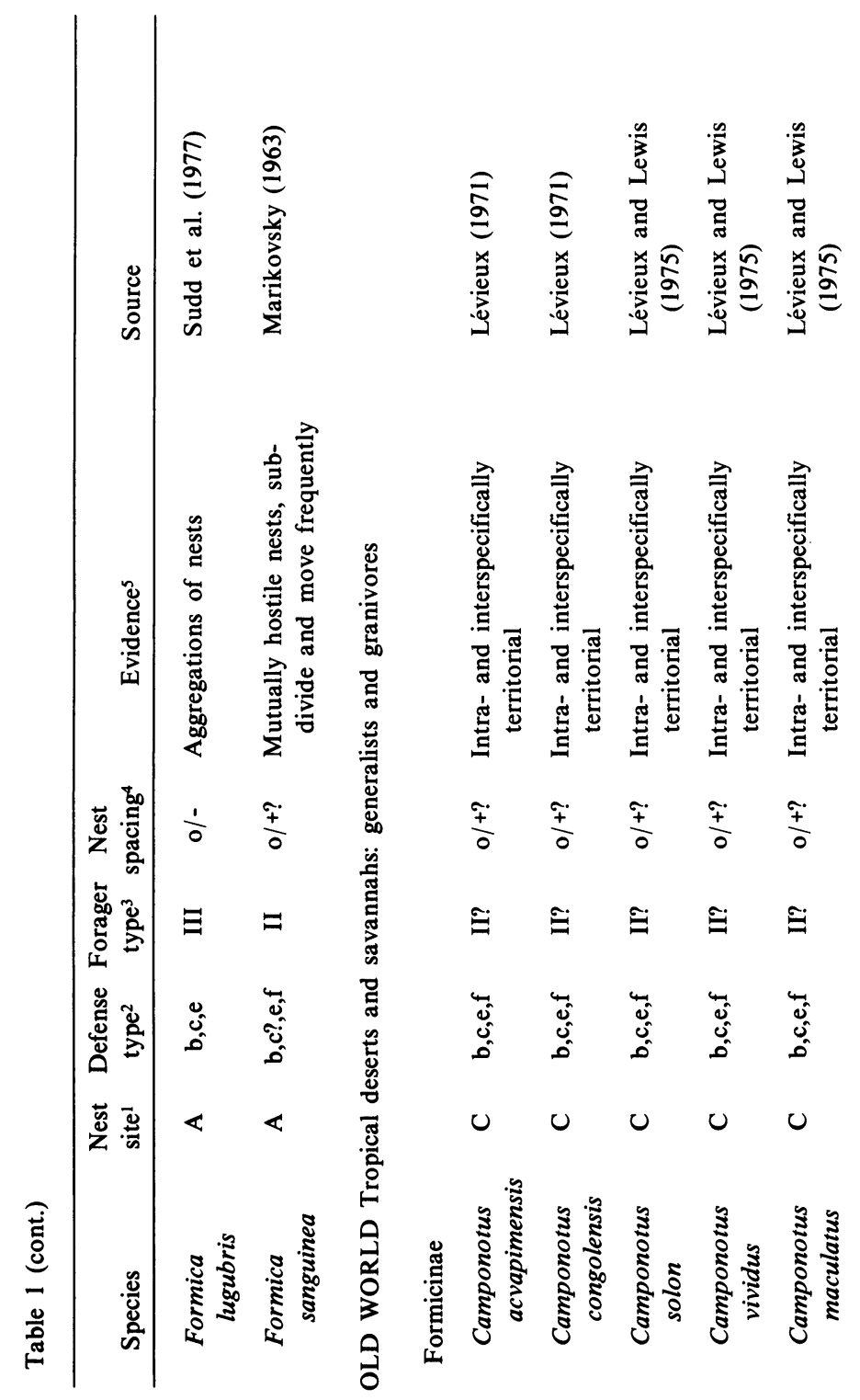




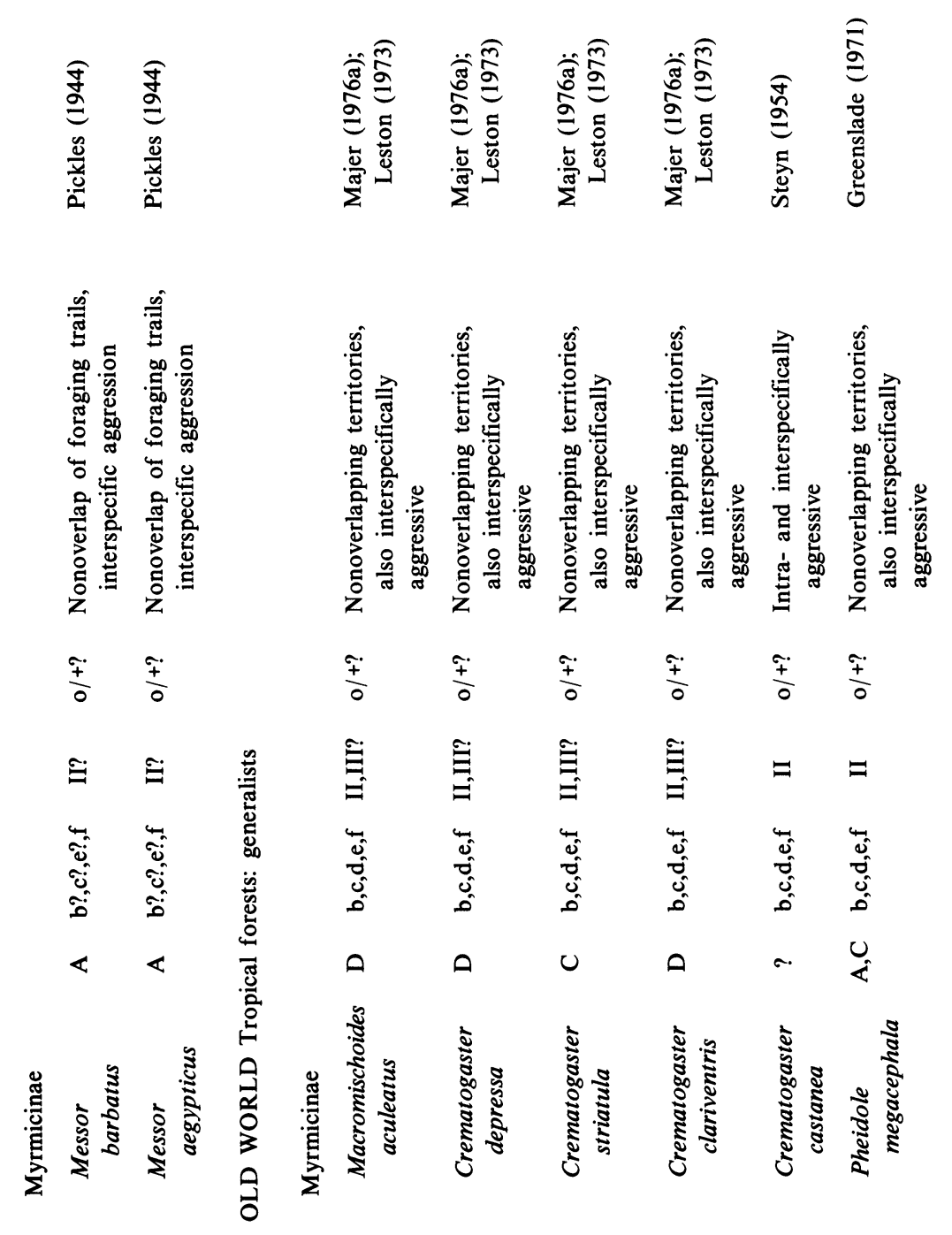




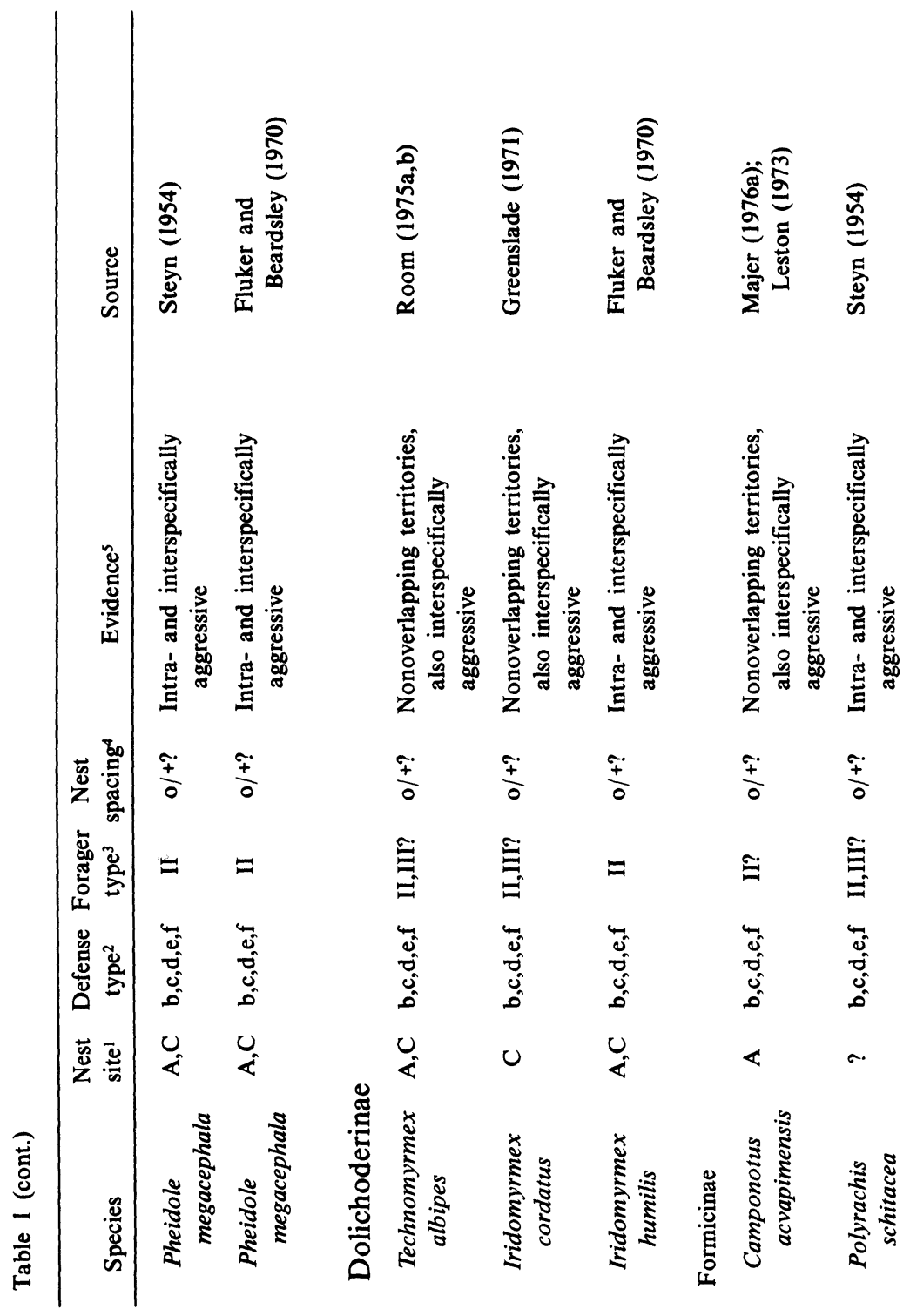



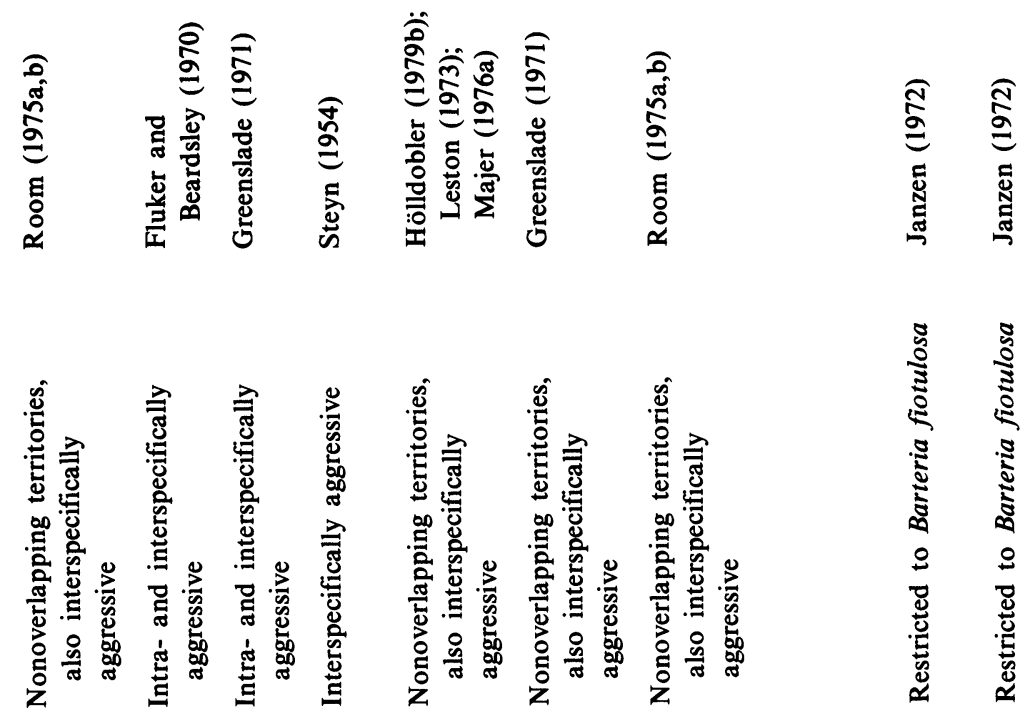

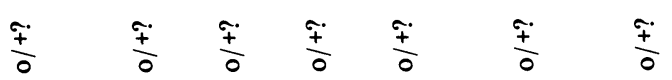

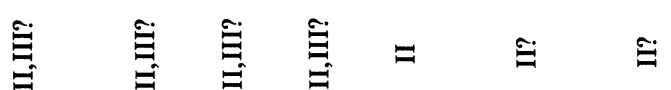

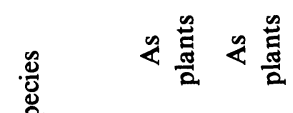

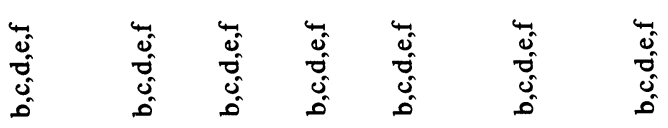

压 气

$\begin{array}{llllll}\infty & \infty & \infty & < & 0 & 0\end{array}$

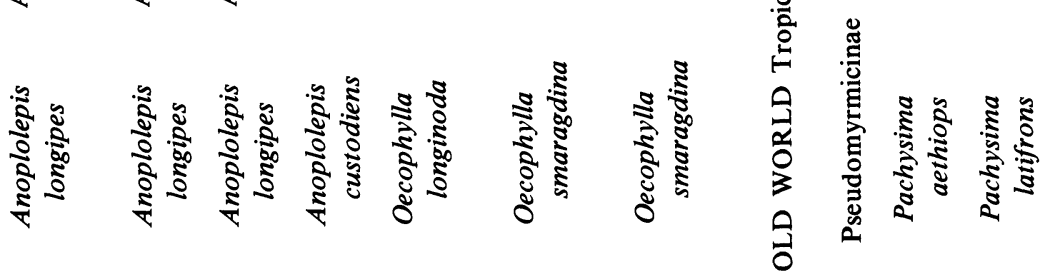




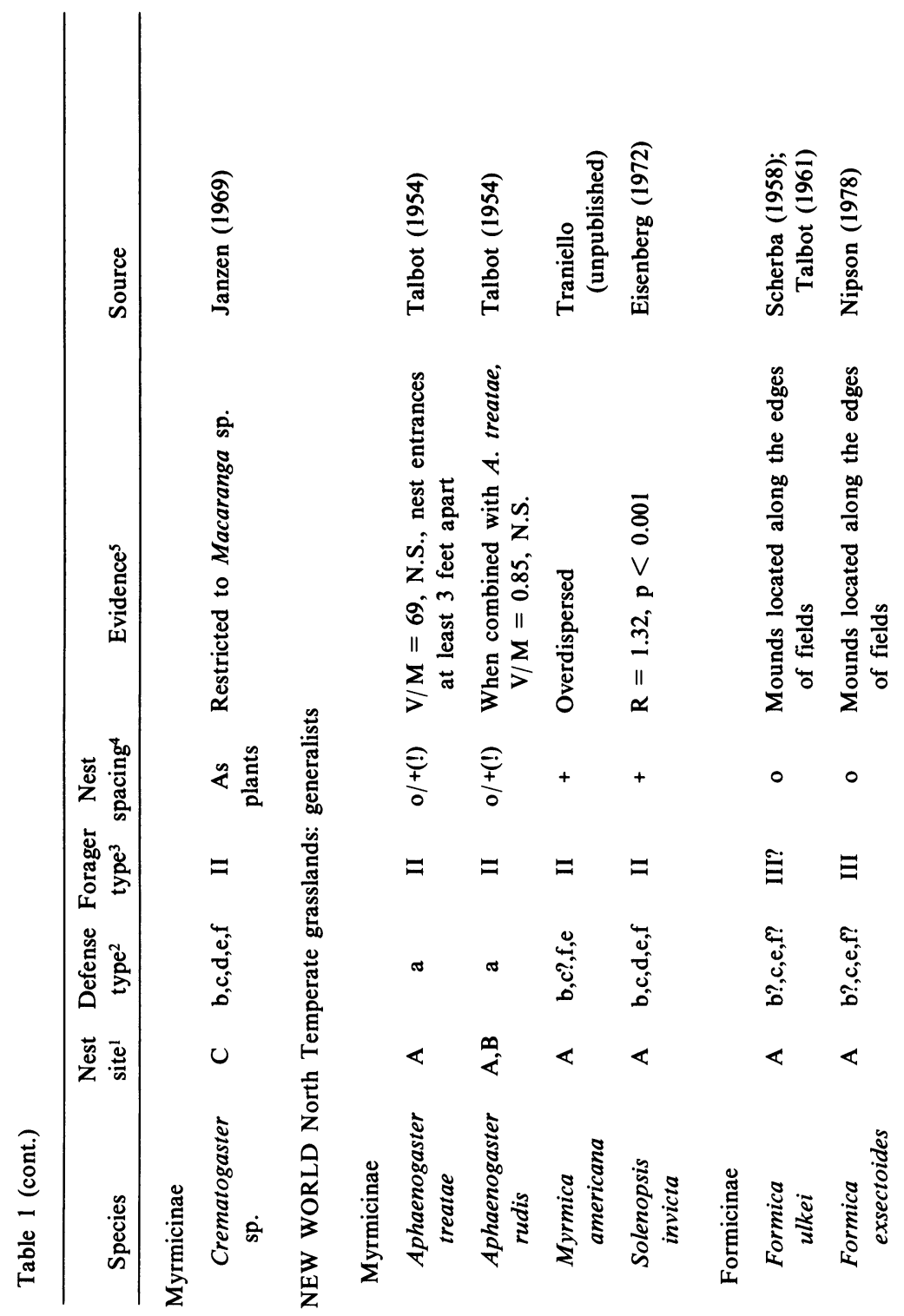



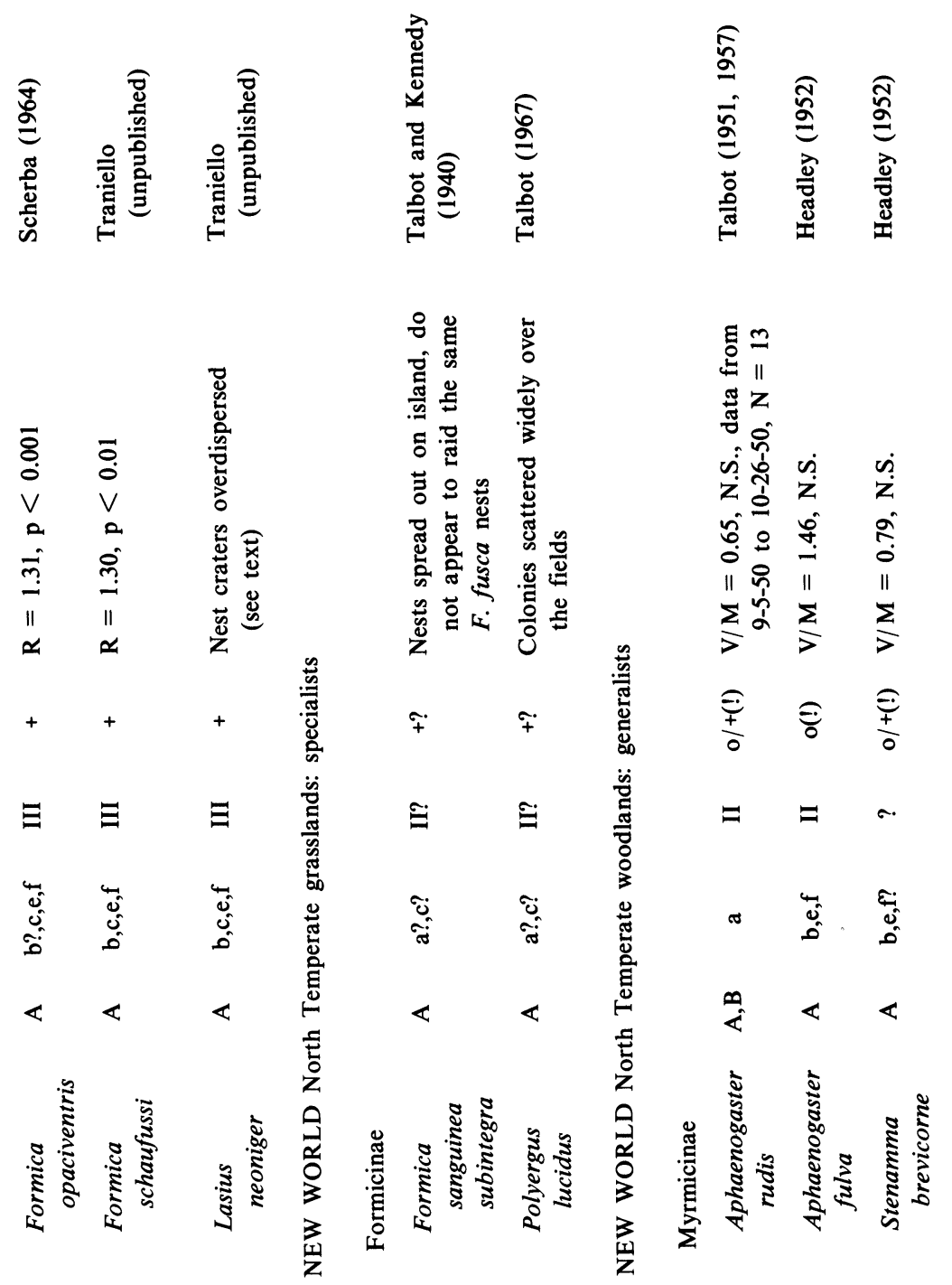
[Vol. 88

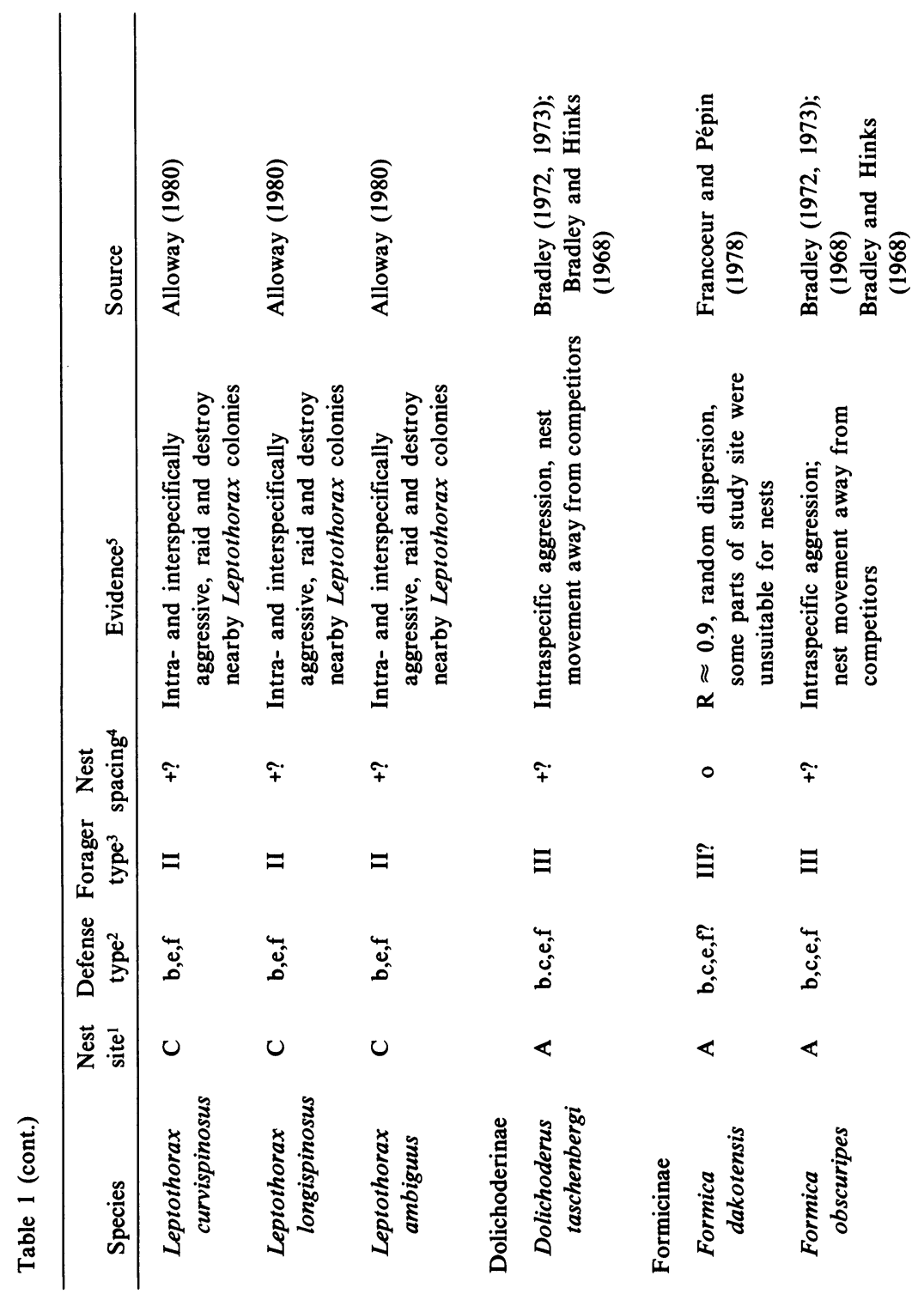



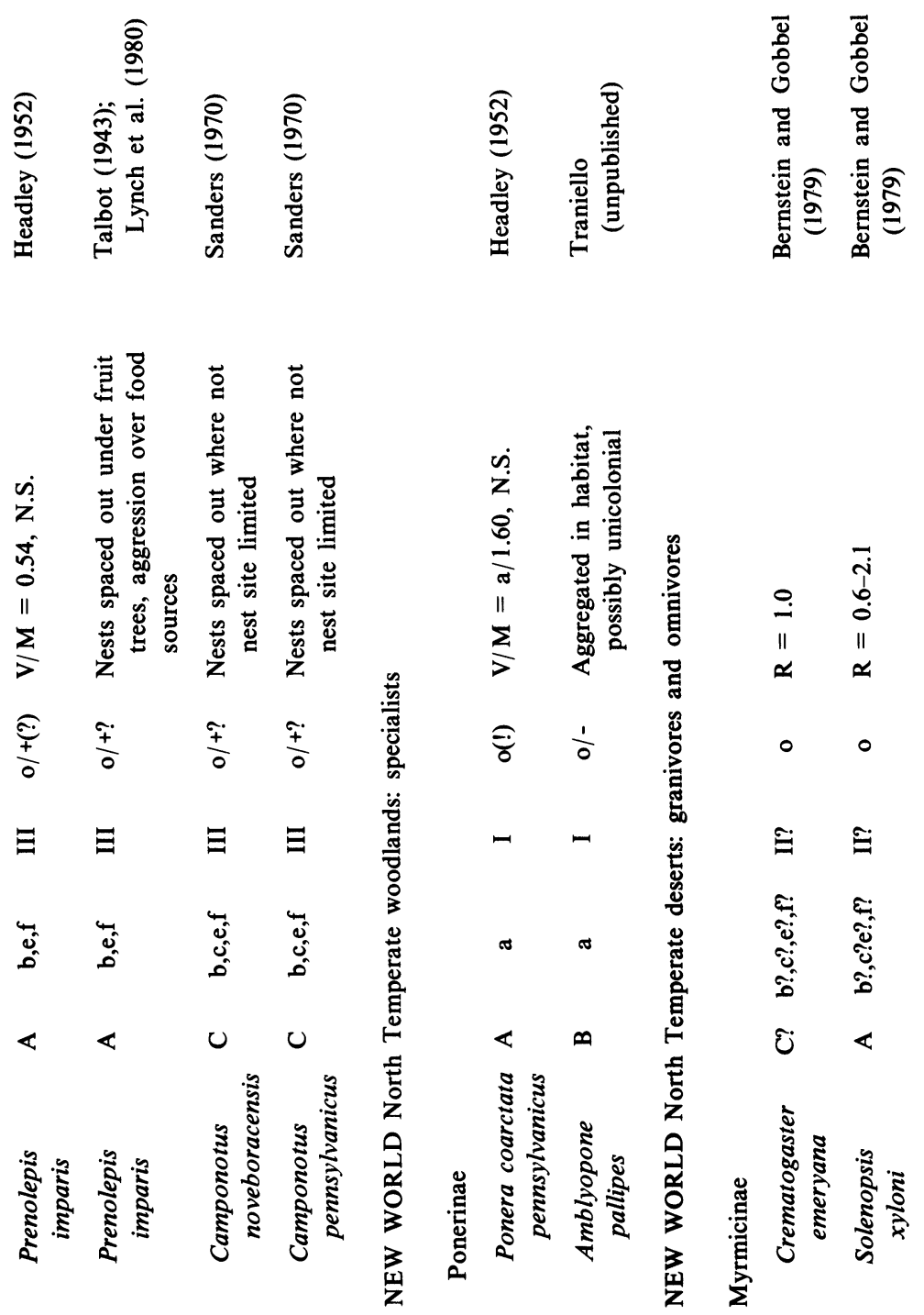


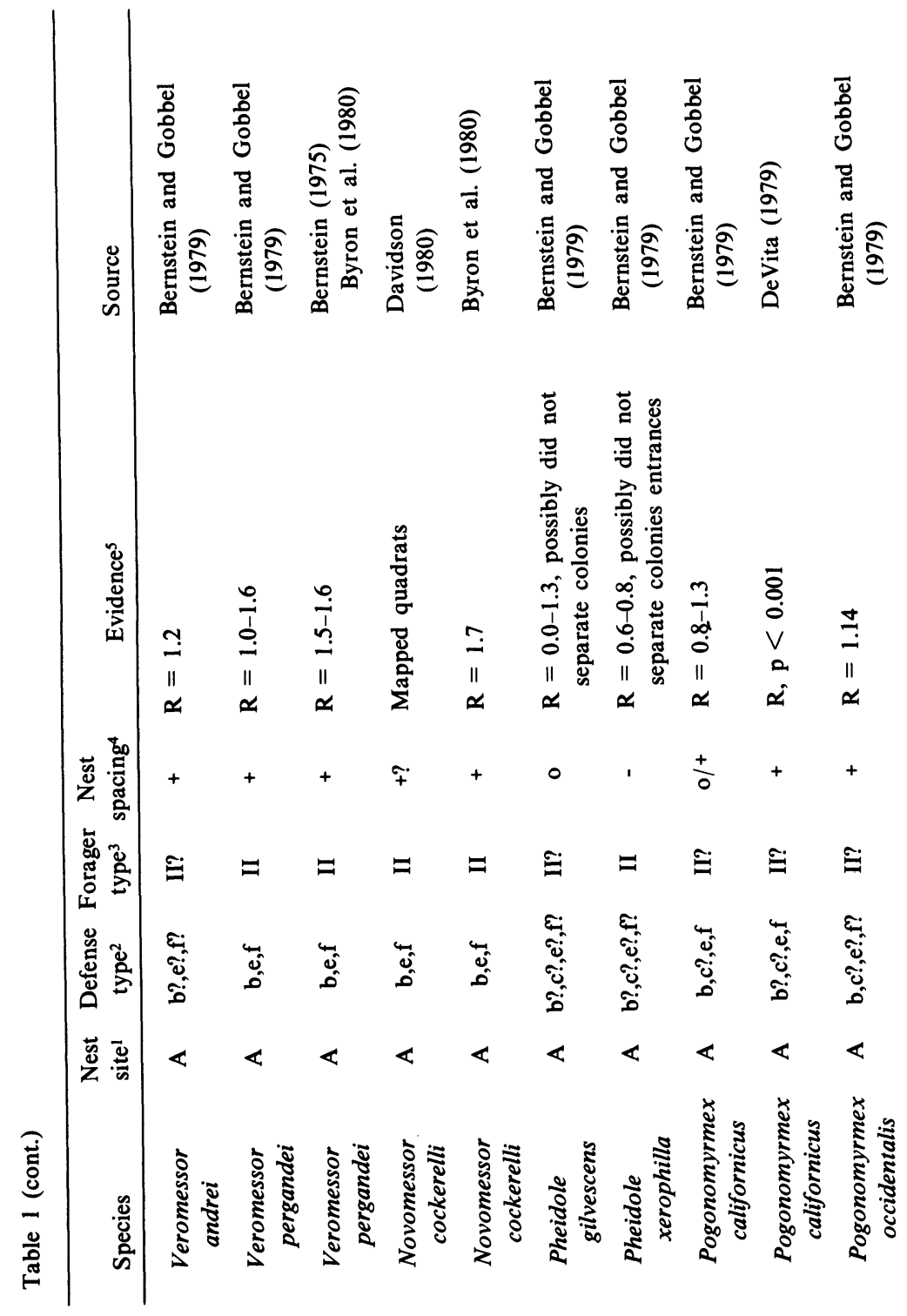




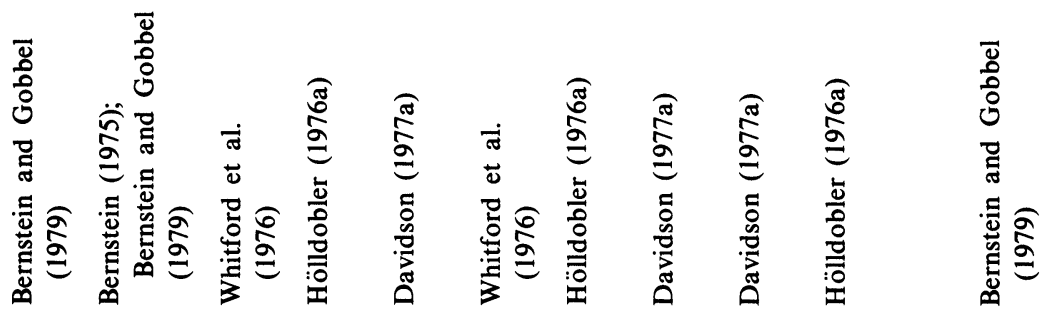

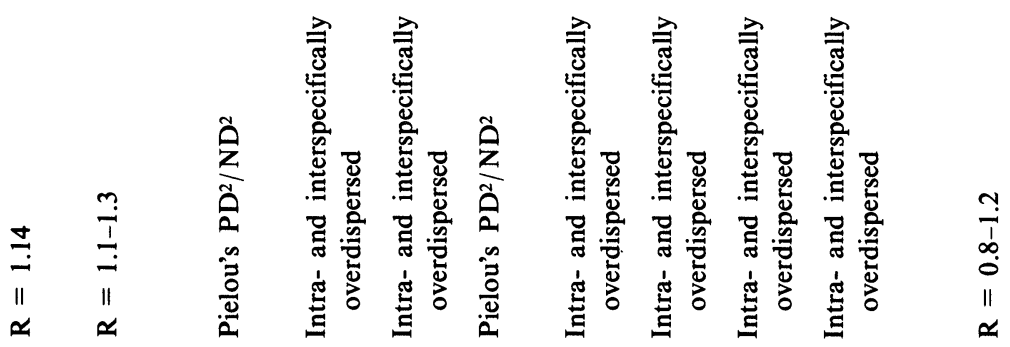

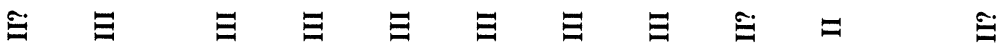

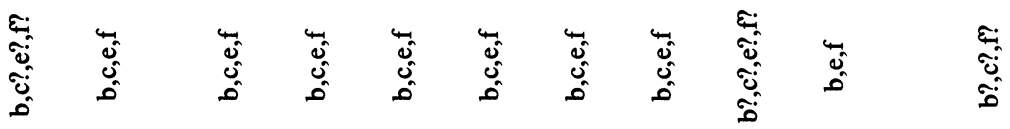

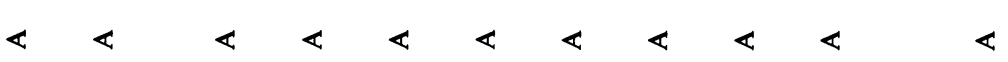

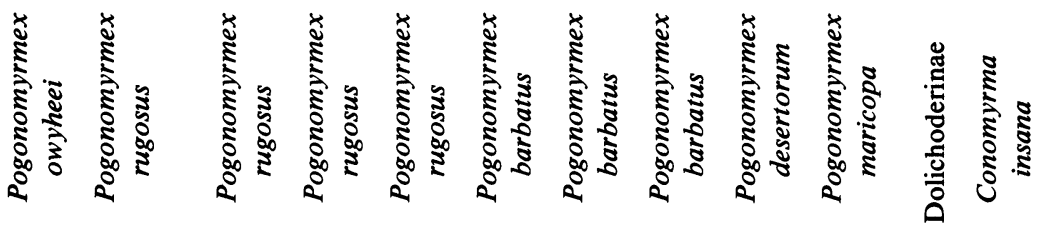




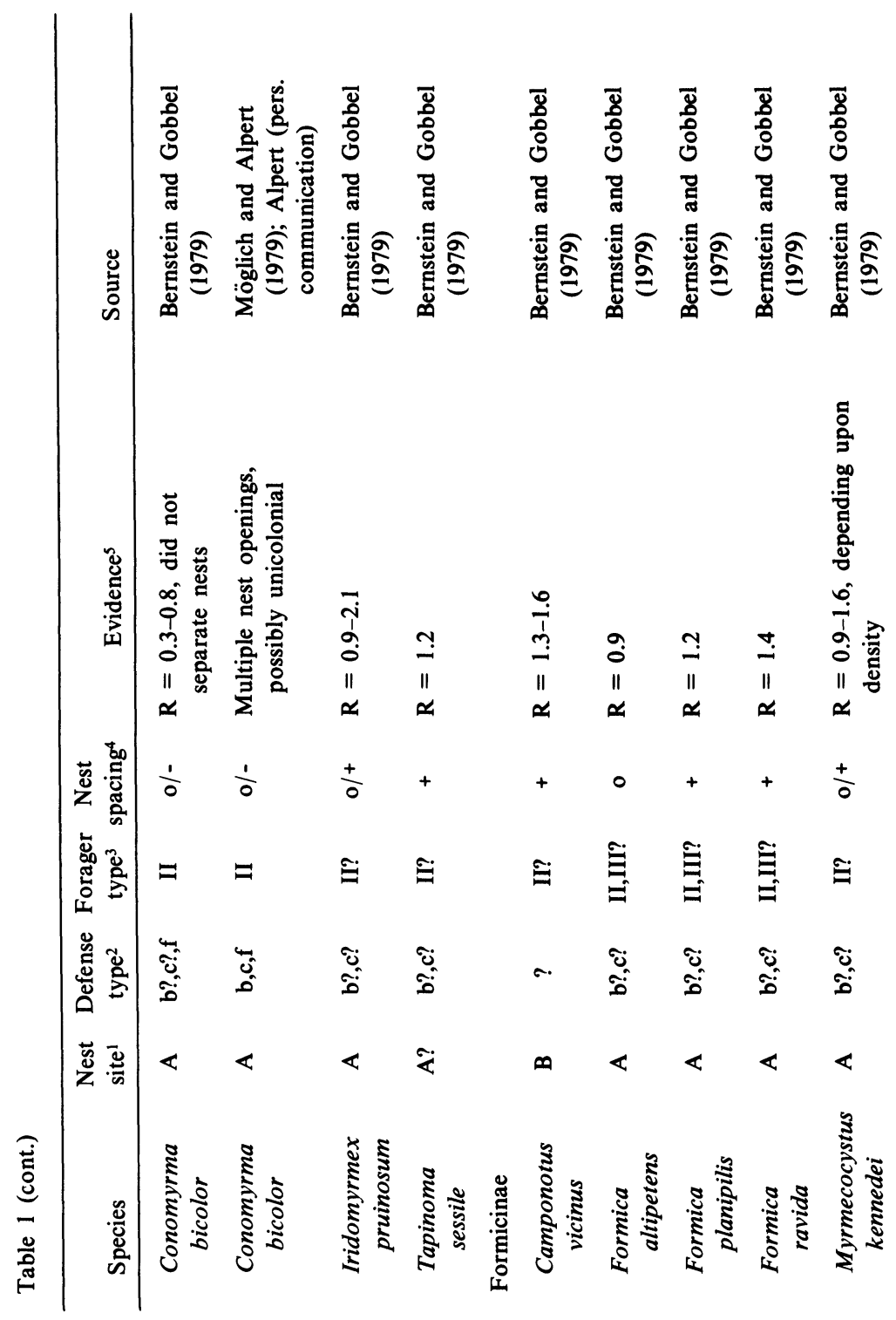



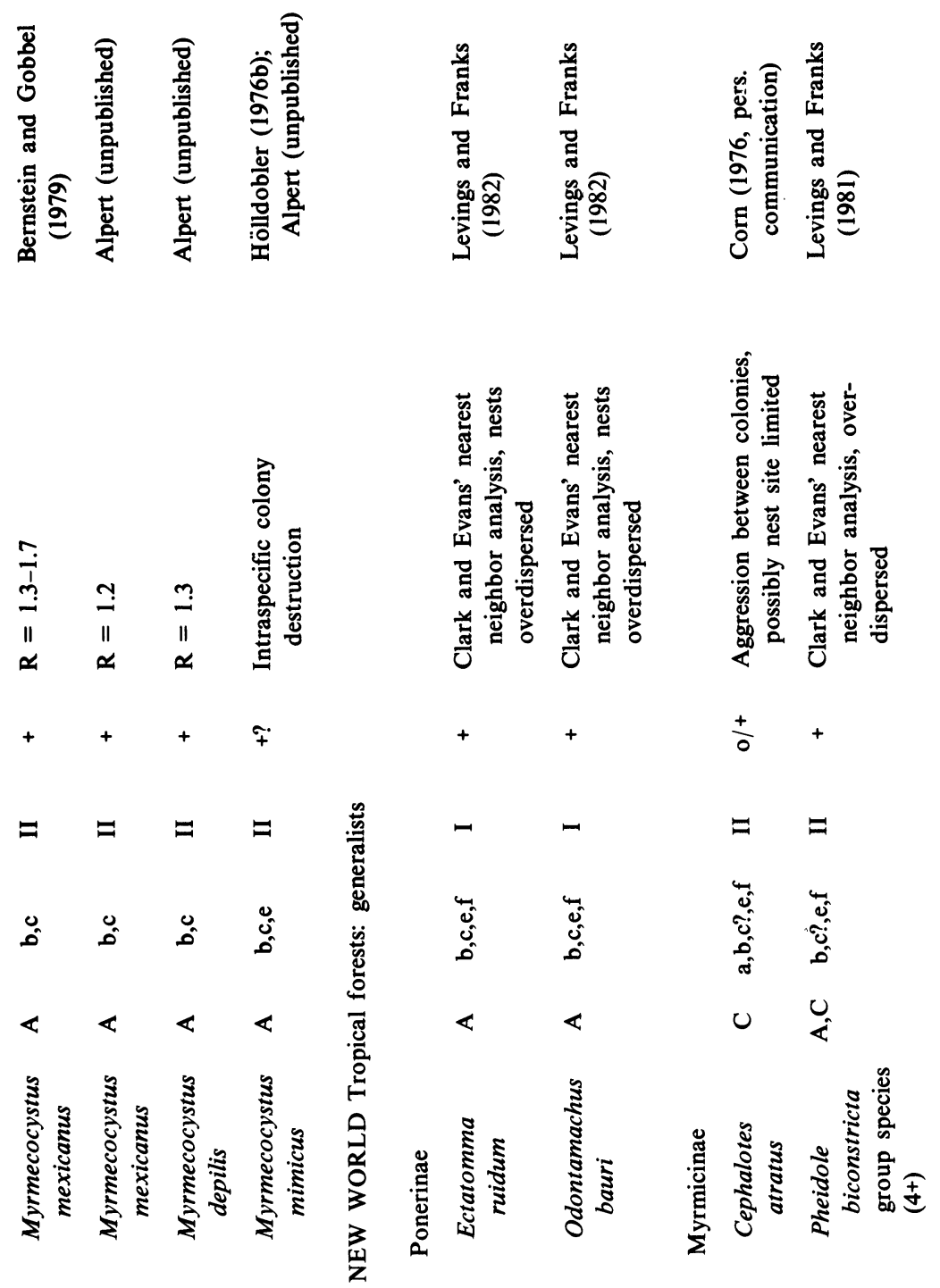


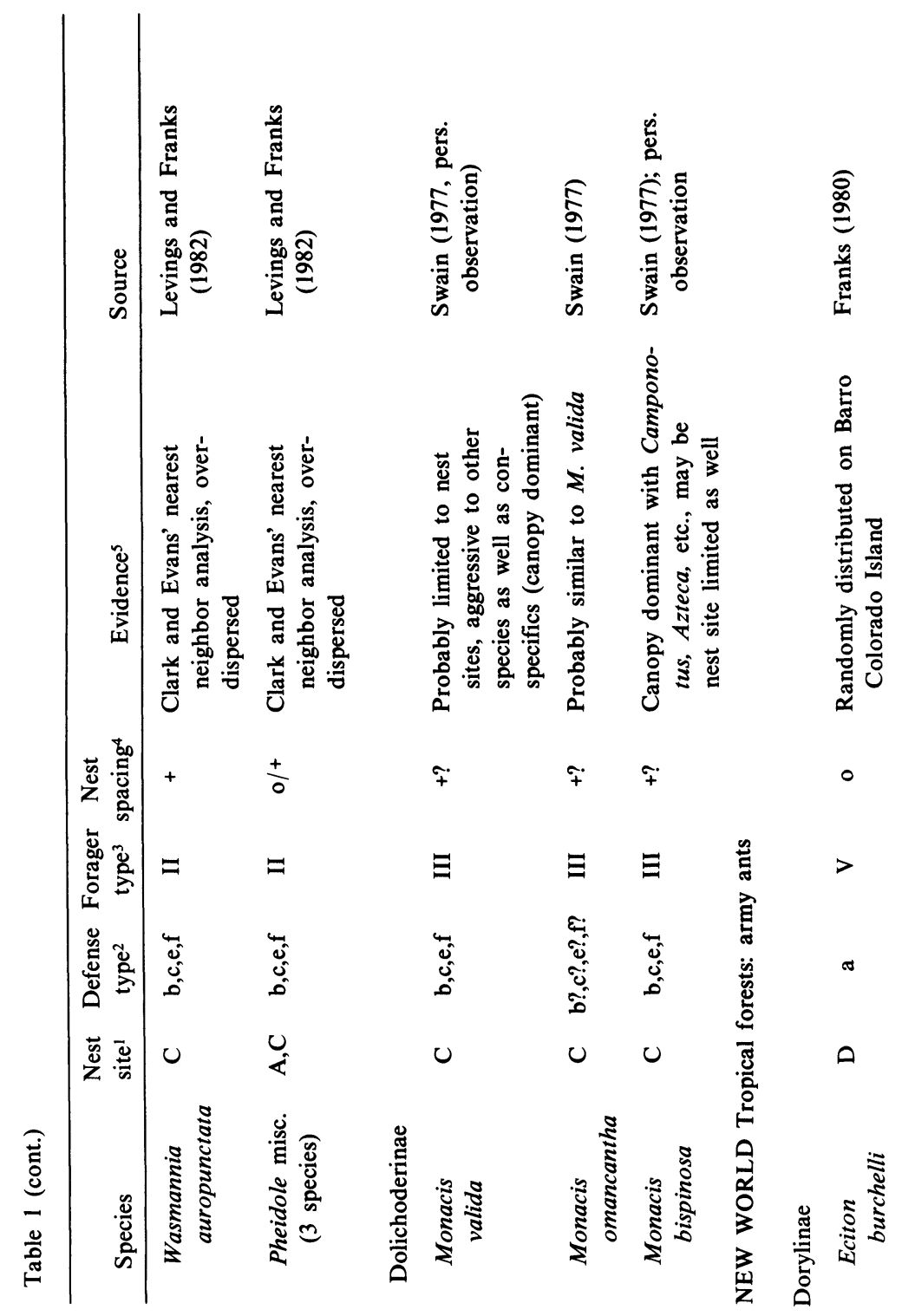




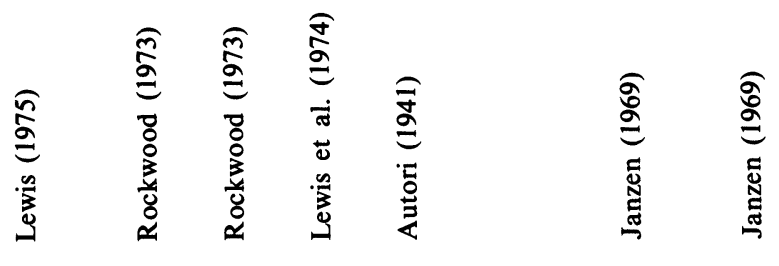

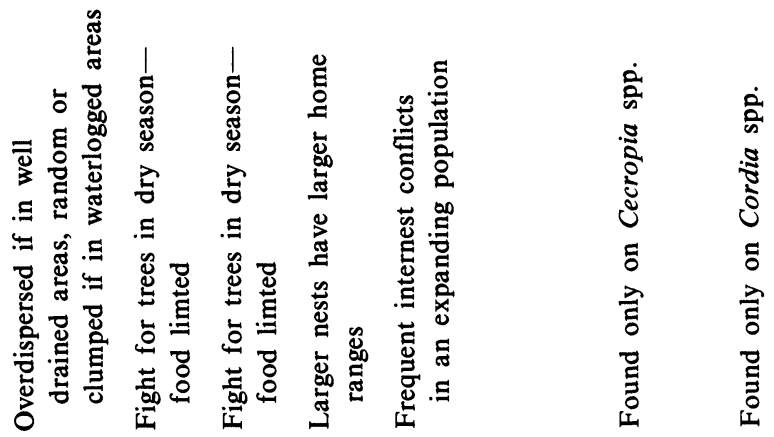

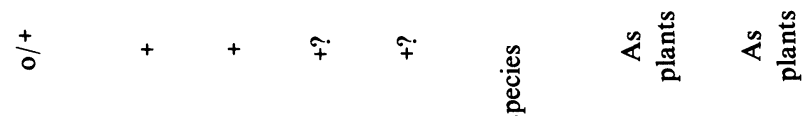

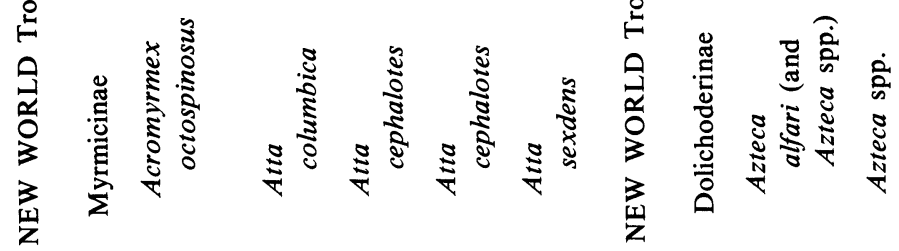




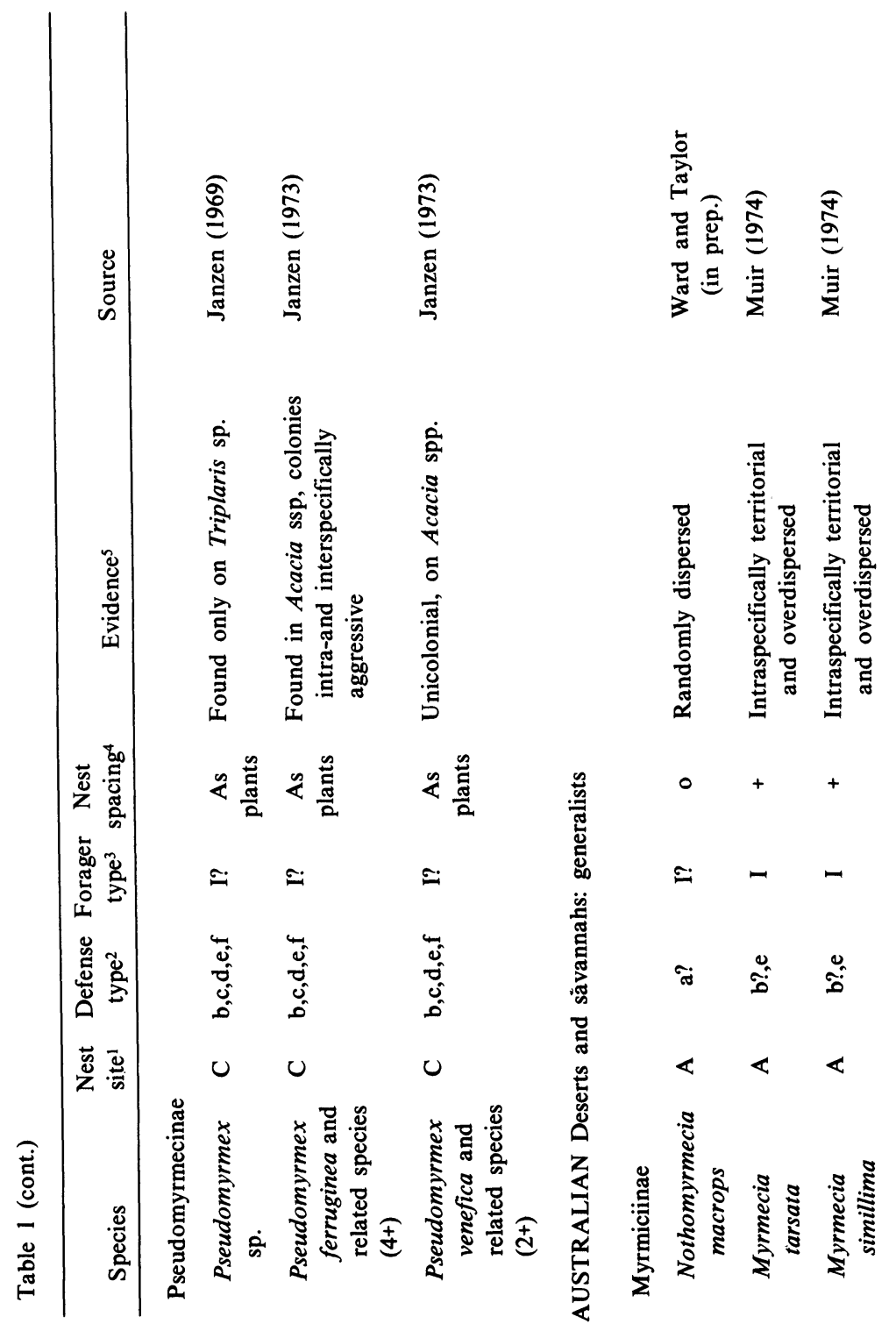




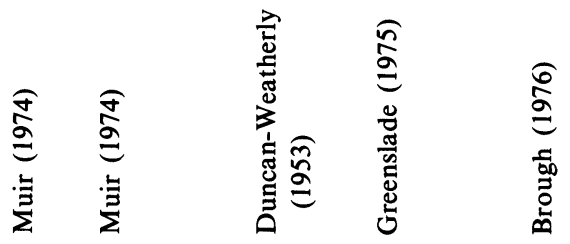
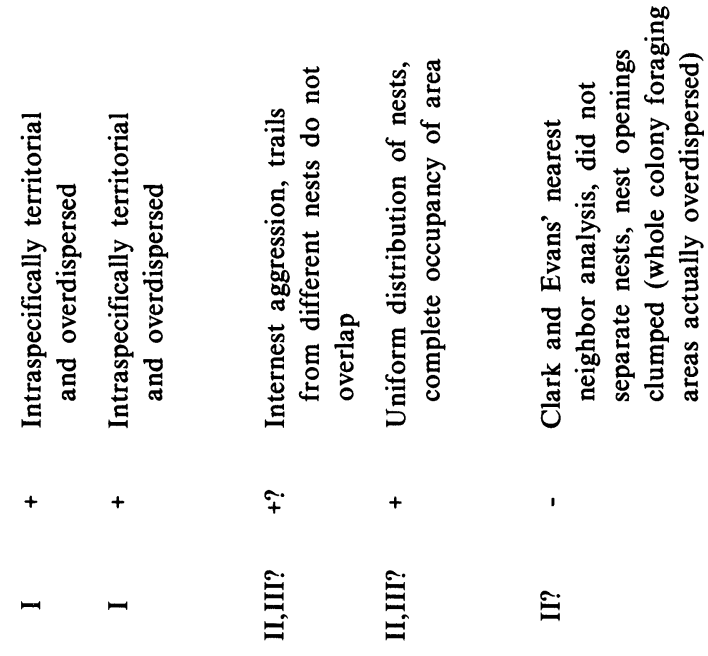

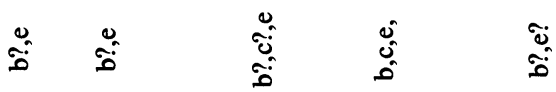
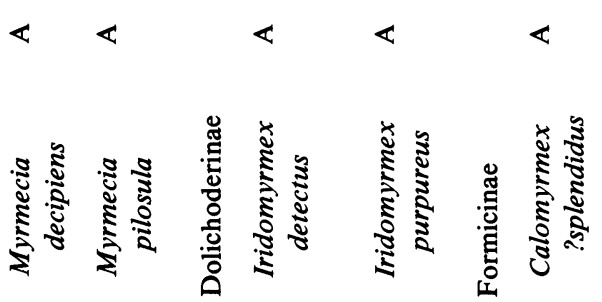


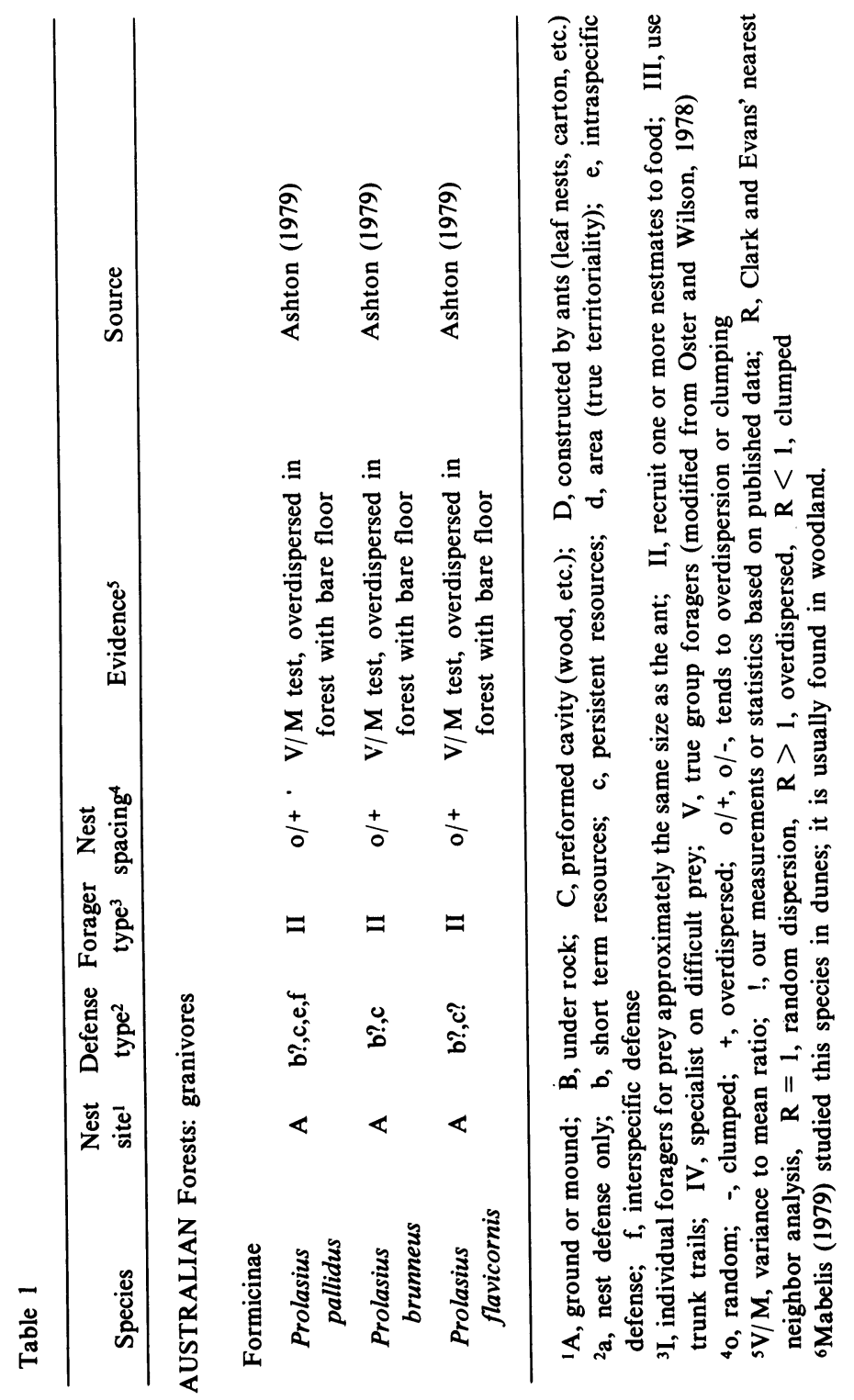


competitors are removed can provide additional evidence for competitive effects on spacing and foraging patterns.

\section{ACKNOWLEDGEMENTS}

This paper is a synthesis of portions of the doctoral dissertations of both authors. We would like to thank the following people for their assistance and helpful criticism: G. Alpert, F.M. Carpenter, N.R. Franks, S.D. Garrity, B. Hölldobler, R. Levins, R. Lewontin, B.L. Thorne, and E.O. Wilson. Supported by the Anderson and Richmond Funds of Harvard University, NSF Grant BNS 80-02613 (B. Hölldobler, sponsor), and NSF predoctoral grants to both authors.

\section{Literature Cited}

ABE, $T$.

1971. On the food sharing among four species of ants in a sandy grassland, I. Food and foraging behavior. Japanese Journal of Ecology 20: 219-230.

adams, E., and J. F. A. Traniello.

1981. Chemical interference competition by Monomorium minimum. Oecologia in press.

Alloway, T. M.

1980. The origin of slavery in leptothoracine ants (Hymenoptera: Formicidae). American Naturalist 115: 247-261.

Ashton, D. H.

1979. Seed harvesting by ants in forests of Eucalyptus regnans F. Muell in central Victoria. Australian Journal of Ecology 4: 265-277.

AUtori, M.

1941. Contribuicão para o conhecimento da saúva (Atta spp. Hymenoptera: Formicidae) (Atta sexdens rubripilosa Forel 1980). Arquivos do Instituto Biologico 12: 197-228.

Baroni-URBani, C.

1969. Ant communities of the high altitude Appenine grasslands. Ecology 50: 488-492.

BARONI-URBANI, C.

1979. Territoriality in social insects. In: The Social Insects, H. R. Hermann, ed. Academic Press, N.Y.

Bernstein, R. A.

1974. Seasonal food abundance and foraging activity in some desert ants. American Naturalist 108: $490-498$.

Bernstein, R. A.

1975. Foraging strategies of ants in response to variable food density. Ecology 56: 213-219.

Bernstein, R. A.

1979. Schedules of foraging activity in species of ants. Journal of Animal Ecology 48: 921-930. 
Bernstein, R. A., ANd M. Gobbel.

1979. Partitioning of space in communities of ants. Journal of Animal Ecology 48: 931-942.

Blackith, R. E., J. W. Siddorn, N. Waloff, and H. F. van Emden.

1963. Mound nests of the yellow ant, Lasius flavus $\mathrm{L}$. on waterlogged pasture in Devonshire. Entomologist's Monthly Magazine 99: 48-49.

Bradley, G. A.

1972. Transplanting Formica obscuripes and Dolichoderus taschenbergi (Hymenoptera: Formicidae) colonies in jack pine stands of southeastern Manitoba. Canadian Entomologist 104: 245-249.

Bradley, G. A.

1973. Interference between nest populations of Formica obscuripes and Dolichoderus taschenbergi (Hymenoptera: Formicidae). Canadian Entomologist 105: 1525-1528.

Bradley, G. A., AND J. D. Hinks.

1968. Ants, aphids and jack pines in Manitoba. Canadian Entomologist 100: 40-50.

BREEN, J.

1979. Nest sites of Formica lugubris (Hymenoptera: Formicidae) in Irish plantation woods. Journal of Life Sciences, Royal Dublin Society 1: 13-32.

BRIAN, M. V.

1952. The structure of a dense natural ant population. Journal of Animal Ecology 21: 12-24.

BRIAN, M. V.

1955. Food collection by a Scottish ant community. Journal of Animal Ecology 24: 336-351.

BRIAN, M. V.

1956a. The natural density of Myrmica rubra and associated ants in west Scotland. Insectes Sociaux 3: 473-487.

BRIAN, M. V.

1956b. Segregation of species of the ant genus Myrmica. Journal of Animal Ecology 25: 319-337.

BRIAN, M. V.

1964. Ant distribution in a southern English heath. Journal of Animal Ecology. 33: 451-461.

Brian, M. V., J. Hibble, and D. Stradling:

1965. Ant pattern and density in a southern English heath. Journal of Animal Ecology 34: 544-555.

Brian, M. V., J. Hibble, and A. F. Kelly.

1966. The dispersion of ant species in a southern English heath. Journal of Animal Ecology 35; 281-290.

\section{BROUGH, E. J.}

1976. Notes on the ecology of an Australian desert species of Calomyrmex (Hymenoptera: Formicidae). Journal of the Australian Entomological Society 15: 339-346. 
Brown, W. L., AND E. O. WiLson.

1959. The evolution of the dacetine ants. Quarterly Review of Biology 34: 278-294.

Byron, P. A., E. R. Byron, and R. A. Bernstein.

1980. Evidence of competition between two species of desert ants. Insectes Sociaux 27: 351-360.

Carroll, R., and D. H. Janzen.

1973. Ecology of foraging by ants. Annual Review of Ecology and Systematics 4: $231-257$.

Cherix, D., AND G. Gris.

1977. The giant colonies of redwood ant in the Swiss Jura (Formica lugubris Zet.). Proceedings of the Eighth International Congress of International Union for the Study of Social Insects. Wageningen, the Netherlands. Centre for Agricultural Publishing and Documentation, Wageningen.

Clark, P. J., and F. C. Evans.

1954. Distance to nearest neighbor as a measure of spatial relationships in populations. Ecology 35: 445-453.

Clark, P. J., and F. C. Evans.

1979. Generalization of a nearest neighbor measure of dispersion for use in $K$. dimensions. Ecology 60: 316-317.

Colwell, R., and D. Futuyma.

1971. On the measurement of niche breadth and overlap. Ecology 52: 567-576.

CORN, M. L.

1976. The ecology and behvior of Cephalotes atratus; a Neotropical ant (Hymenoptera: Formicidae). Unpublished Ph.D. dissertation, Harvard University.

Culver, D.

1974. Species packing in Caribbean and north temperate ant communities. Ecology 55: 974-988.

Davidson, D.

1977a. Species diversity and community organization in desert seed-eating ants. Ecology 58: 711-724.

Davidson, D.

1977b. Foraging ecology and community organization in desert seed-eating ants. Ecology 58: 725-737.

Davidson, D.

1980. Some consequences of diffuse competition in a desert ant community. American Naturalist 116: 92-105.

DeVita, J.

1979. Mechanisms of interference and foraging among colonies of the harvester ant Pogonomyrmex californicus in the Mojave desert. Ecology 60: 729-737.

DeVroey, C.

1979. Aggression and Gausse's Law in ants. Physiological Entomology 4: $217-222$.

Diver, C.

1935. A population of wood ants (Formica sp.) at Abernethy. Journal of Animal Ecology 4: 32-34. 
DobrzansKa, J.

1958. Partition of foraging grounds and modes of conveying information among ants. Acta Biologiae Experimentalis, (Warsaw) 18: 55-67.

DOBRZANSKa, J.

1966. The control of territory by Lasius fuliginosus Latr. Acta Biologiae Experimentalis, (Warsaw) 26: 193-213.

Duncan-Weatherly, A. H.

1953. Some aspects of the biology of the mound ant Iridomyrmex detectus. Australian Journal of Zoology 1: 178-192.

EISENBERG, R. M.

1972. Partitioning of space among colonies of the fire ants, Solenopsis saevissima, I. Spatial arrangement. Texas Journal of Science 24: 39-43.

Elmes, G. W.

1971. An experimental study on the distribution of heathland ants. Journal of Animal Ecology 40: 495-499.

Elmes, G. W.

1974. The spatial distribution of a population of two ant species living in limestone grassland. Pedobiologia 14: 412-418.

ELton, C. S.

1932. Territory among wood ants (Formica rufa L.) at Picket Hill. Journal of Animal Ecology 1: 69-76.

Fluker, S. S., AND J. W. BeARdsley.

1970. Sympatric associations of three ants: Iridomyrmex humilis, Pheidole megacephala and Anoplolepis longipes in Hawaii. Annals of the Entomological Society of America 63: 1290-1296.

Fran"coeur, A., and D. Peppin.

1978. Productivitep de la fourmi Formica dakotensis dans la pessiepre tourbeuse. 2. Variations annuelles de la densitep des colonies, de l'occupation des nids et de la repartition spatiale. Insectes Sociaux 25: 13-30.

Franks, N.

1980. The evolutionary ecology of the army ant Eciton burchelli on Barro Colorado Island, Panama. Unpublished Ph.D. dissertation, The University of Leeds, Leeds, England.

Greenslade, P. J. M.

1971. Interspecific competition and frequency changes among ants in the Solomon Islands coconut plantations. Journal of Applied Ecology 8: 323-352.

Greenslade, P. J. M.

1975. Dispersion and history of a population of the meat ant Iridomyrmex purpureus (Hymenboptera: Formicidae). Australian Journal of Zoology 23: $495-510$.

Headley, A. E.

1941. A study of the nest and nesting habits of the ant Lasius niger subsp. alienus var. americanus Emery. Annals of the Entomological Society of America 34: 649-657.

Headley, A. H.

1952. Colonies of ants in a locust woods. Annals of the Entomological Society of America 45: 435-442. 
Higashi, S., and K. Yamauchi.

1979. Influence of a supercolonial ant Formica (Formica) yessensis on the distribution of other ants in Ishikari Coast. Japanese Journal of Ecology 29: $257-264$.

HöLLDOBLER, B.

1973. Chemische strategie beim nahrungserwerb der Diebsameise (Solenopsis fugax Latr.) und der Pharaoameise (Monomorium pharoanis L.) Oecologia 11: $371-380$.

HÖLLDOBLER, B.

1974. Home range orientation and territoriality in harvesting ants. Proceedings of the National Academy of Sciences, USA 71: 3274-3277.

HöLLDOBLER, B.

1976a. Recruitment behavior, home range orientation and territoriality in harvesting ants. Behavioral Ecology and Sociobiology 1: 3-44.

HÖLLDOBLER, B.

1976b. Tournaments and slavery in a desert ant. Science 192: 912-914.

HöLLDOBLER, B.

1977. Communication in social Hymenoptera. Pp. 418-471 in T. A. Sebeok, ed., How animals communicate. Indiana University Press, Bloomington.

HöLLDOBLER, B.

1979a. Territoriality in ants. Proceedings of the American Philosophical Society 123: $211-218$.

HöLLDOBLER, B.

1979b. Territories of the African weaver ant (Oecophylla longinoda (Latreille)):

A field study. Zeitschrift für Tierpsychologie 51: 201-213.

HöLLDOBLER, B., AND C. LUMSDEN.

1980. Territorial strategies in ants. Science 210: 732-739.

HöLLDOBLER, B., AND M. Möglich.

1980. The foraging system of Pheidole militicida. Insectes Sociaux 27: 237264.

Hölldobler, B., AND E. O. Wilson.

1970. Recruitment trails in the harvester ant Pogonomyrmex badius. Psyche 77: 385-399.

HölldobleR, B., AND E. O. WILSON.

1977a. Weaver ants: social establishment and maintenance of territory. Science 195: $900-902$.

Hölldobler, B., AND E. O. Wilson.

1977b. Colony-specific territorial pheromone in the African weaver ant Oecophylla longinoda (Latreille). Proceedings of the National Academy of Science, USA 74: 2072-2075.

HÖlLDOBLER, B., AND E. O. Wilson.

1977c. The number of queens: an important trait in ant evolution. Naturwissenschaften 64: 8-15.

Hölldobler, B., Stanton, R. C., and H. Markl.

1978. Recruitment and food-retrieving behavior in Novomessor (Formicidae, Hymenoptera) I. Chemical signals. Behavioral Ecology and Sociobiology 4: 163-181. 
HUNT, J.

1974. Temporal activity patterns in two competing ant species (Hymenoptera: Formicidae). Psyche 81: 237-242.

Ito, M., and S. Imamura.

1974. Observations on the nuptial flight and internidal relationship in a polydomous ant, Formica (F.) yessensis Forel. Journal of the Faculty of Science, Hokkaido University, Series VI, Zoology 19: 681-694.

JANZEN, D. H.

1967. Interaction of the bull's-horn acacia (Acacia cornigera L.) with an ant inhabitant (Pseudomyrmex ferruginea $\mathrm{F}$. Smith) in eastern Mexico. Kansas University Science Bulletin 47: 315-558.

JANZEN, D. H.

1969. Allelopathy by myrmecophytes: the ant Azteca as an allelopathic agent of Cecropia. Ecology 50: 147-153.

JANZEN, D. H.

1972. Protection of Barteria (Passifloraceae) by Pachysima ants (Pseudomyrmicinae) in a Nigerian rain forest. Ecology 53: 885-892.

JANZEN, D. H.

1973. Evolution of polygynous obligate acacia ants in western Mexico. Journal of Animal Ecology 42: 727-750.

JANZEN, D. H.

1975. Pseudomyrmex nigropilosa: A parasite of a mutualism. Science 188: 936-937.

LESTON, D.

1973. The ant mosaic in tropical tree crops and the limiting of pests and diseases. Pest Articles and News Summaries 19: 311-341.

LeVIEUX, J.

1971. Mise en epvidence de la structure des nids et de l'implantation des zones de chasse de deux espeQces de Camponotus (Hym., Form.) aQ l'aide de radio-isotopes. Insectes Sociaux 18: 29-48.

LevieuX, J.

1977. La nutrition des fourmis tropicales: V. Elepments de syntheQse. Les modes d'exploitation de la biocoenose. Insectes Sociaux 24: 235-260.

Levieux, J., AND D. LouIs.

1975. La nutrition des fourmis tropicales. II. Comportement alimentaire et regime de Camponotus vividus (Smith) (Hymenoptera: Formicidae). Comparison intragénérique. Insects Sociaux 22: 391-404.

Levings, S. C., and N. R. Franks.

1982. Patterns of nest dispersion in a tropical ground ant community. Ecology, 63 in press.

Levings, S. C., AND D. M. Windsor.

1982. Seasonal and annual variation in litter arthropod populations. In E. G. Leigh, A. S. Rand, and D. M. Windsor, eds., The ecology of a tropical forest: seasonal rhythms and longer term changes. Smithsonian Institution Press, Washington, D.C. In press.

LEwIS, T.

1975. Colony size, density and distribution of the leaf cutting ant, Acromyr- 
mex octospinosus (Reich) in cultivated fields. Transactions of the Royal Entomological Society of London 127: 51-64.

Lewis, T., G. V. Pollard, and G. C. Dibley.

1974. Rhythmic foraging in the leaf cutting ant Atta cephalotes. Journal of Animal Ecology 43: 129-141.

LynCh, J., E. C. Balinsky, and S. G. Vail.

1980. Foraging patterns in three sympatric forest ant species, Prenolepis imparis, Paratrechina melanderi and Aphaenogaster rudis (Hymenoptera: Formicidae). Ecological Entomology 5: 353-371.

Mabelis, A. A.

1979. The relationship between aggression and predation in the red wood ant (Formica polyctena Forrst.). Netherlands Journal of Zoology 29: 451-620.

MacArthur, R. H., AND R. LeVins.

1967. The limiting similarity, convergence and divergence of coexisting species. American Naturalist 101: 377-385.

MAJER, J. D.

1976a. The maintenance of the ant mosaic in Ghana cocoa farms. Journal of Applied Ecology 13: 123-144.

MAJER, J. D.

1976b. The ant mosaic in Ghana cocoa farms: further structural considerations. Journal of Applied Ecology 13: 145-153.

MARKL, H., AND B. HólLDobler.

1978. Recruitment and food-retrieving behavior in Novomessor (Formicidae, Hymenoptera) II. Vibration Signals. Behavioral Ecology and Sociobiology 4: $183-216$.

MarikovsKy, P. I.

1963. The ant Formica sanguinea Latr. as pillagers of Formica rufa Lin. nests. Insectes Sociaux 10: 119-128.

Morglich, M., and G. Alpert.

1979. Stone-dropping by Conomyrma bicolor: a new kind of interference behavior in ants. Behavioral Ecology and Sociobiology 6: 105-114.

MUIR, R. J.

1974. A study of the coexistence of four sympatric species of Myrmecia (Formicidae). Unpublished Ph.D. dissertation, University of New England, Armidale, New South Wales, Australia.

Nipson, H. E.

1978. Inbreeding in the ant species Formica exsectoides. Unpublished Ph.D. dissertation, Harvard University.

OSTER, G., AND E. O. WILSON.

1978. Caste and ecology in the social insects. Princeton University Press, Princeton, N.J.

Petal, J.

1972. Methods of investigating the productivity of ants. Ekologia Polska 20: 9-22.

Petal, $\mathbf{J}$.

1977. The effect of food supply and intraspecific competition in an ant 
population. Proceedings of the Eighth International Congress of the International Union for the Study of Social Insects, 5-10 September 1977, Wageningen, The Netherlands, pp. 60-61.

Pianka, E. R.

1978. Evolutionary ecology, 2nd ed. Harper and Row, New York.

Pickles, W.

1944. Territories and interrelations of two ants of the genus Messor in Algeria. Journal of Animal Ecology 13: 128-129.

Pielou, E. C.

1977. Mathematical ecology, 2nd ed. John Wiley, New York.

Pisarski, B.

1972. La structure des colonies polycaliques de Formica (Coptoformica) exsecta Nyl. Ekologia Polska 20: 113-116.

Pontin, A. J.

1960. Field experiments on colony foundation by Lasius niger (1.) and Lasius flavus (F.) (Hym., Formicidae). Insectes Sociaux 7: 227-230.

Pontin, A. J.

1961. Field experiments on colony foundation by Lasius niger (L.) and $L$.

Pontin, A. J. flavus (F.) (Hym.: Formicidae). Journal of Animal Ecology 38: 47-54.

1963. Further consideration of competition and the ecology of the ants Lasius flavus (F.) and L. niger (L.). Journal of Animal Ecology 32: 565-574.

Pontin, A. J.

1969. Experimental transplantation of nest mounds of the ant Lasius flavus (F.) in a habitat containing also L. niger (L.) and Myrmica scabrinodis Nyl. Journal of Animal Ecology 38: 747-754.

Poole, R. E.

1974. An introduction to quantitative ecology. McGraw-Hill, New York.

Reichman, O. J.

1979. Desert granivore foraging and its impact on seed densities and distribution. Ecology 60: 1085-1092.

Robertson, P. L.

1971. Pheromones involved in aggressive behavior in the ant Myrmecia gulosa. Journal of Insect Physiology 17: 691-715.

Rockwood, L.

1973. Distribution, density and dispersion of two species of Atta (Hymenoptera: Formicidae) in Guanacoste Province, Costa Rica. Journal of Animal Ecology 42: 803-807.

Room, P. M.

1971. The relative distributions of ant species in Ghana's cocoa farms. Journal of Animal Ecology 40: 735-751.

Room, P. M.

1975a. Relative distributions of ant species in cocoa plantations in Papua, New Guinea. Journal of Applied Ecology 12: 47-61.

Room, P. M.

1975b. Diversity and organization of the ground foraging ant faunas of forest, grassland and tree crops in Papua, New Guinea. Australian Journal of Zoology 23: 71-89. 
SANDERS, C. J.

1970. The distribution of carpenter ant colonies in the spruce fir forests of northwestern Ontario. Ecology 51: 865-873.

SCHERBA, G.

1958. Reproduction, nest orientation and population structure of an aggregation of mound nests of Formica ulkei, Emery (Formicidae). Insectes Sociaux 5: 201-213.

SCHERBA, G.

1964. Species replacement as a factor affecting distribution of Formica opaciventris Emery (Hymenoptera: Formicidae). Journal of the New York Entomological Society 72: 231-237.

SChNeIRla, T. C.

1971. Army ants: a study in social organization. W. H. Freeman and Co., San Francisco.

SCHOENER, T.

1971. Theory of feeding strategies. Annual Review of Ecology and Systematics 2: 369-404.

SimberlofF, D. S.

1979. Nearest neighbor assessments of spatial configurations of circles rather than points. Ecology 60: 679-685.

SKINNER, G. H.

1980. Territory, trail structure and activity patterns in the wood ant, Formica rufa (Hymenoptera: Formicidae) in limestone woodland in northwest England. Journal of Animal Ecology 49: 381-394.

Stebaev, I., AND J. I. Reznikova.

1972. Two interaction types of ants living in steppe ecosystem in South Siberia, USSR. Ekologia Polska 20: 103-109.

STEYN, J. J.

1954. The pugnacious ant (Anoplolepis custodiens Smith) and its relation to the control of citrus scales at Letaba. Memoirs of the Entomological Society of South Africa 3: 1-96.

Sudd, J. H., T. M. Douglas, T. Gaynard, D. M. Murray, and J. M. Stockdale.

1977. The distribution of wood ants (Formica lugubris Zetterstedt) in a northern English forest. Ecological Entomology 2: 301-313.

SWAIN, R.

1977. The natural history of Monacis, a genus of Neotropical ants. Unpublished Ph.D. dissertation, Harvard University.

TALBOT, M.

1943. Population studies of the ant Prenolepis imparis. Ecology 24: 31-44.

TALBOT, M.

1951. Population and hibernating conditions of the ant Aphaenogaster (Attomyrma) rudis Emery (Hymenoptera: Formicidae). Annals of the Entomological Society of America 44: 302-307.

TALBOT, $M$.

1954. Populations of the ant Aphaenogaster (Attomyrma) treatae Forel on abandoned fields on the Edwin S. George Reserve. Contribution from the Laboratory of Vertebrate Biology of the University of Michigan, no. 69, pp. 1-9. 
TALBOT, M.

1957. Populations of ants in a Missouri woodland. Insectes Sociaux 4: 375-384.

TALBOT, M.

1961. Mounds of the ant Formica ulkei at the Edwin S. George Reserve, Livingston County, Michigan. Ecology 42: 202-205.

TALBOT, $M$.

1967. Slave raids of the ant Polyergus lucidus Mayr. Psyche 74: 299-313.

TAlbot, M. and C. H. KenNedy.

1940. The slave making ant, Formica sanguinea subintegra Emery, its raids, nuptial flights and nest structure. Annals of the Entomological Society of America 32: 304-315.

Thorne, B. L., AND K. P. Sebens.

1981. Regulation of social insect colony size: a model based on foraging energetics. Unpublished manuscript.

Traniello, J. F. A.

1980. Studies on the behavioral ecology of north temperate ants. Unpublished Ph.D. dissertation, Harvard University.

Waloff, N., aNd R. E. Blackith.

1962. The growth and distribution of mounds of Lasius flavus (F.) (Hymenoptera: Formicidae) in Silwood Park, Berkshire. Journal of Animal Ecology 31: 421-437.

WARD, P. S., AND R. W. TAYLOR.

1981. Allozyme variation, colony structure and genetic relatedness in a primitive ant Nothomyrmecia macrops (Hymenoptera: Formicidae).

WAY, M. J. Unpublished manuscript.

1953. The relationship between certain ant species with particular reference to biological control of the coreid, Theraptus sp. Bulletin of Entomological Research 45: 93-112.

Whitford, W. G., E. Depree, and P. Johnson.

1980. Foraging ecology of two Chihuahuan desert ant species: Novomessor cockerelli and N. albisetosus. Insectes Sociaux 27: 148-156.

Whitford, W. G., P. Johnson, and J. Ramirez.

1976. Comparative ecology of the harvester ants Pogonomyrmex barbatus and $P$. rugosus. Insectes Sociaux 23: 117-132.

Wilson, E. O.

1959a. Communication by tandem running in the ant genus Cardiocondyla. Psyche 66: 29-34.

WILSON, E. O.

1959b. Some ecological characteristics of ants in New Guinea rain forests. Ecology 40: 437-447.

WILSON, E. O.

1971. The insect societies. Belknap Press of Harvard University Press, Cambridge, Mass.

WILSON, E. O.

1975. Enemy specification in the alarm-recruitment system of an ant. Science 190: $798-800$. 
Wilson, N. L., J. H. Diller, and G. P. Markin.

1972. Foraging territories of imported fire ants. Annals of the Entomological Society of America 64: 660-665.

YASUNO, M.

1963. The study of the ant population in the grassland at Mt. Hakkoda. I. The distribution and the abundance of ants in the grassland. Ecological Review 16: 83-91.

Yasuno, M.

1964a. The study of the ant population in the grassland at Mt. Hakkoda, II. The distribution pattern of ant nests at the Kayano grassland. Science Reports of the Tohoku University, Sendai, Japan, ser. 4 (Biol.) 39: 43-55.

YASUNO, M.

1964b. The study of the ant population in the grassland at Mt. Makkoda, III. The effect of the slave making ant, Polyergus samurai, upon the nest distribution pattern of the slave ant, Formica fusca japonica. Science Reports of the Tohoko University, Sendai, Japan, ser. 4 (Biol.) 30: 167-170.

Yasuno, M.

1965. Territory of ants in the Kayano grassland at Mt. Hakkoda. Science Reports of the Tohoko University, Sendai Japan, ser 4 (Biol.) 31: 195-206. 

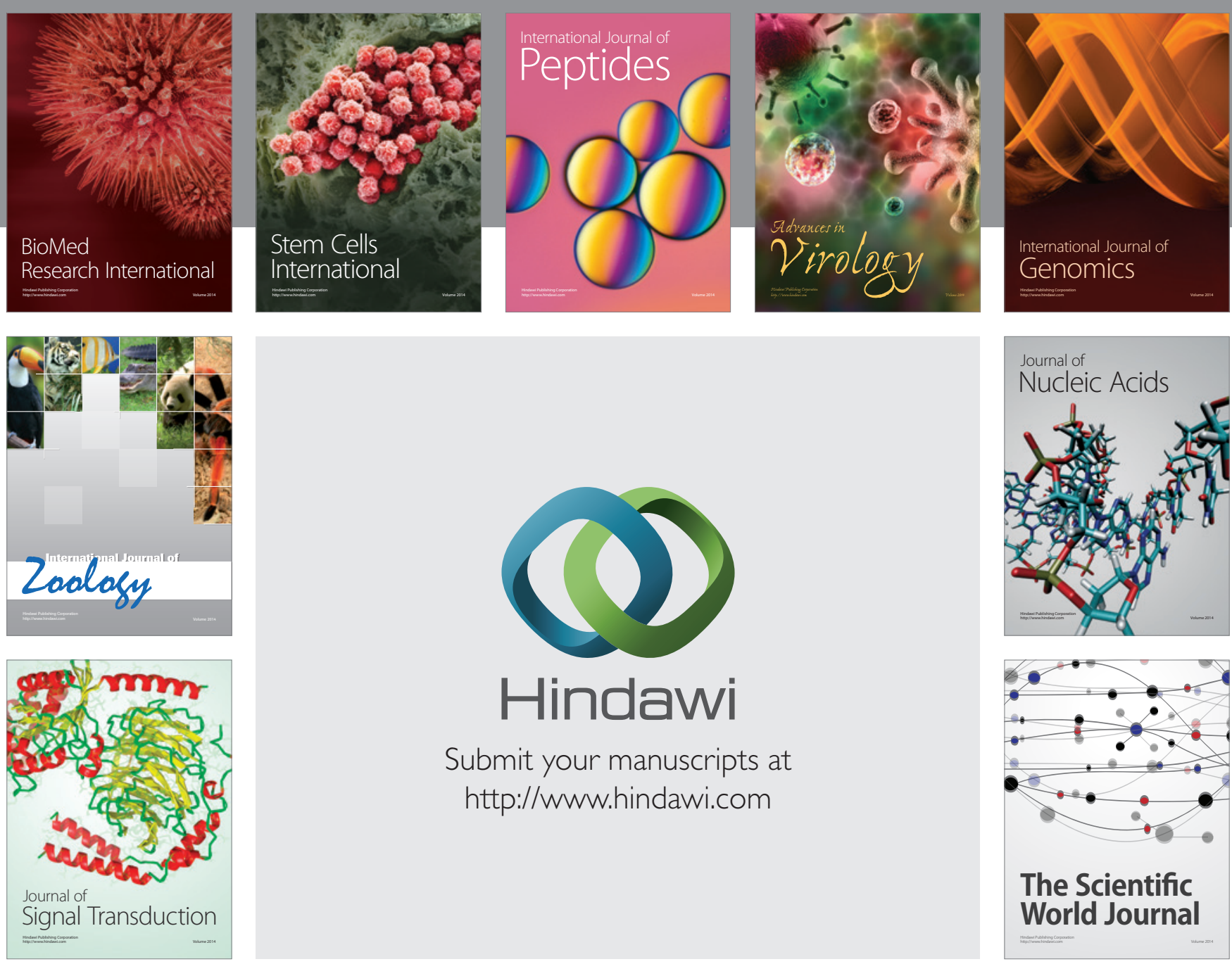

Submit your manuscripts at

http://www.hindawi.com
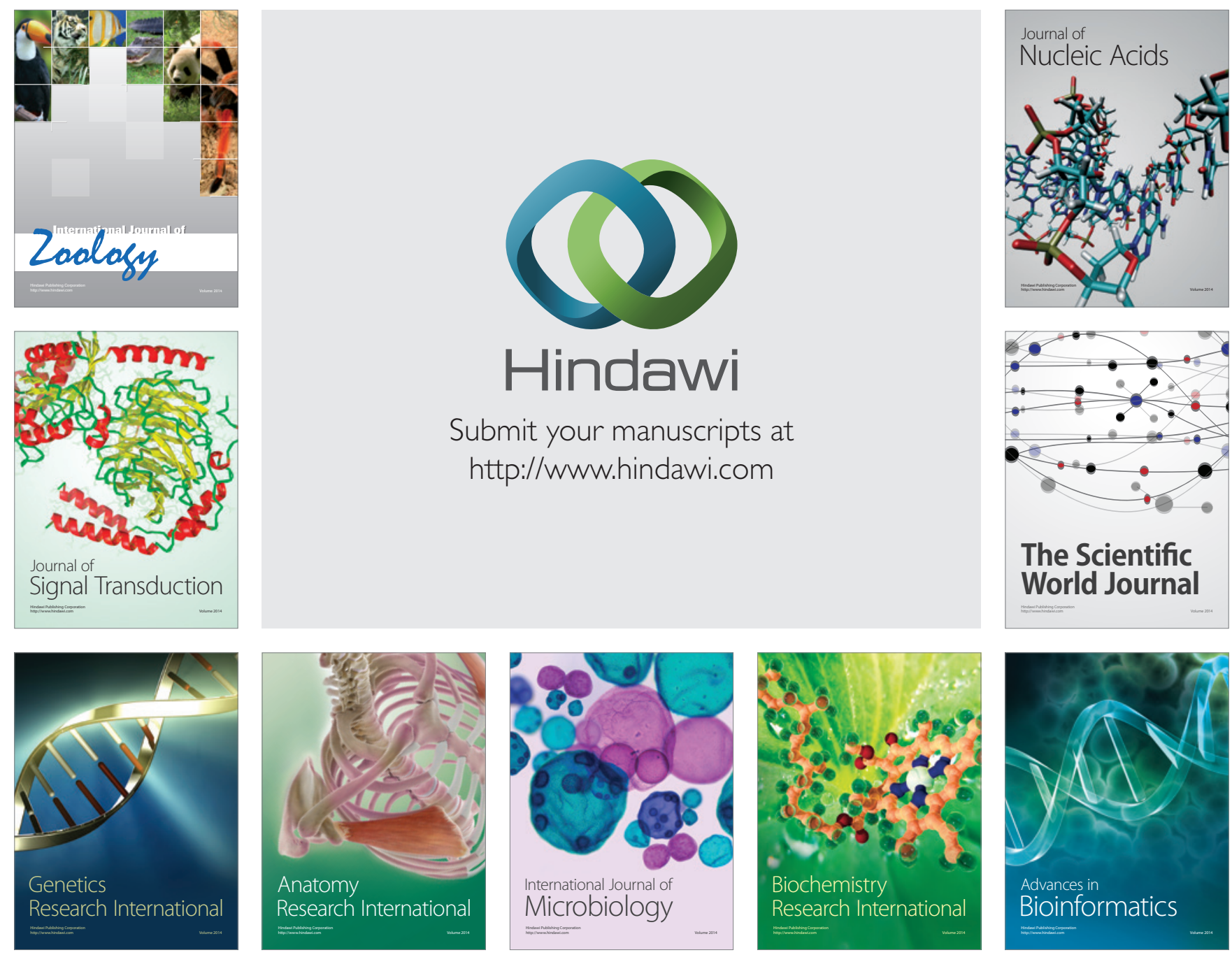

The Scientific World Journal
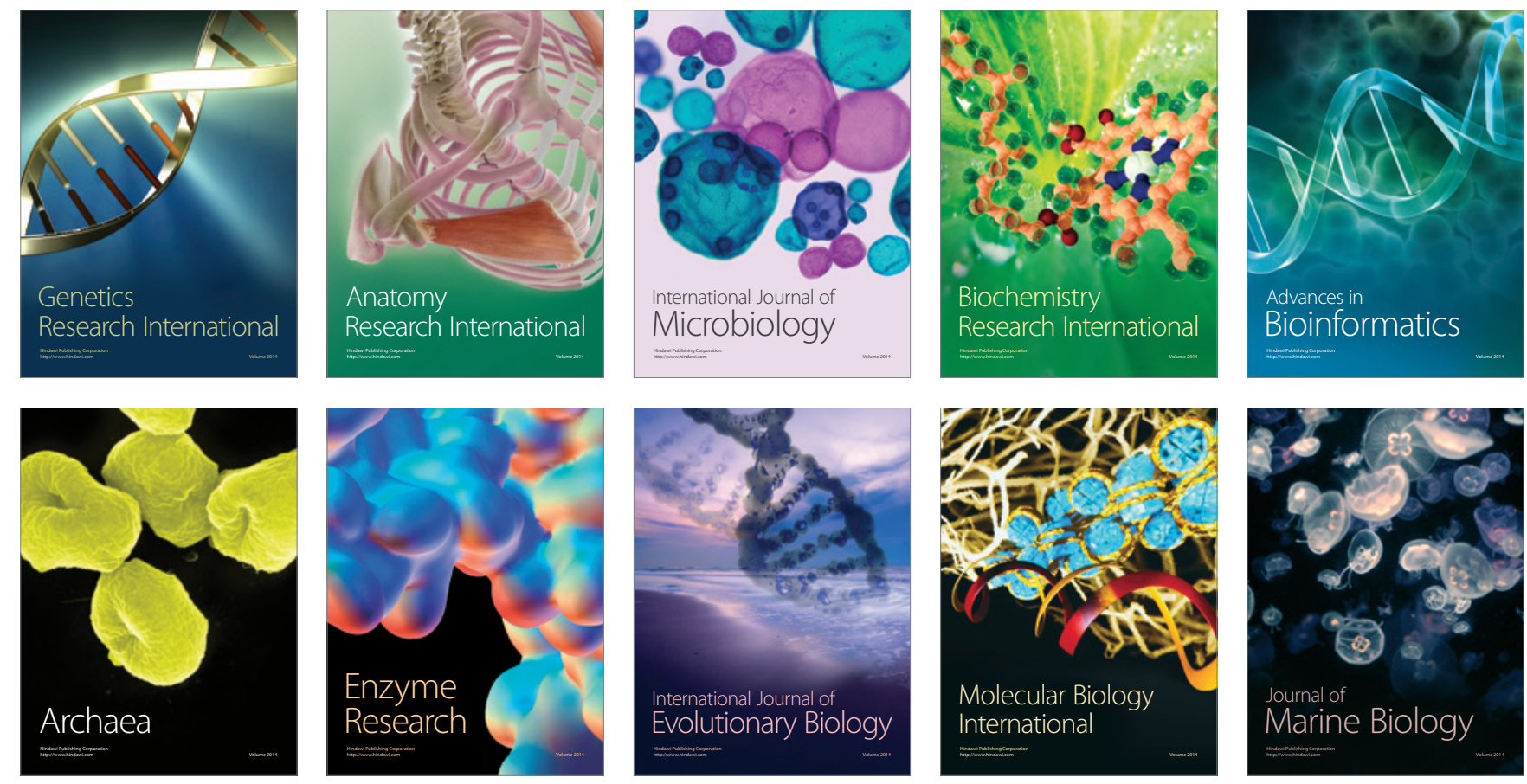